\title{
The Effect of Anthropogenic Aerosols on the Aleutian Low
}

\author{
William J. Dow, ${ }^{\mathrm{a}}$ Amanda C. MAycock, ${ }^{\mathrm{a}}$ MArcus Lofverstrom, ${ }^{\mathrm{b}}$ And Christopher J. Smith ${ }^{\mathrm{a}, \mathrm{c}}$ \\ ${ }^{\text {a }}$ School of Earth and Environment, University of Leeds, Leeds, United Kingdom \\ ${ }^{\mathrm{b}}$ Department of Geosciences, The University of Arizona, Tucson, Arizona \\ ${ }^{\mathrm{c}}$ International Institute for Applied Systems Analysis, Laxenburg, Austria
}

(Manuscript received 8 June 2020, in final form 17 November 2020)

\begin{abstract}
Past studies have suggested that regional trends in anthropogenic aerosols can influence the Pacific decadal oscillation (PDO) through modulation of the Aleutian low. However, the robustness of this connection is debated. This study analyzes changes to the Aleutian low in an ensemble of climate models forced with large, idealized global and regional black carbon (BC) and sulfate aerosol perturbations. To isolate the role of ocean feedbacks, the experiments are performed with an interactive ocean and with prescribed sea surface temperatures. The results show a robust weakening of the Aleutian low forced by a global tenfold increase in BC in both experiment configurations. A linearized steady-state primitive equation model is forced with diabatic heating anomalies to investigate the mechanisms through which heating from BC emissions influences the Aleutian low. The heating from BC absorption over India and East Asia generates Rossby wave trains that propagate into the North Pacific sector, forming an upper-tropospheric ridge. Sources of BC outside of East Asia enhance the weakening of the Aleutian low. The responses to a global fivefold and regional tenfold increase in sulfate aerosols over Asia show poor consistency across climate models, with a multimodel mean response that does not project strongly onto the Aleutian low. These findings for a large, idealized step increase in regional sulfate aerosol differ from previous studies that suggest the transient increase in sulfate aerosols over Asia during the early twenty-first century weakened the Aleutian low and induced a transition to a negative PDO phase.
\end{abstract}

KEYWORDS: Rossby waves; Aerosols/particulates; Model comparison; Primitive equations model; Pacific decadal oscillation

\section{Introduction}

The Pacific decadal oscillation (PDO) is a major mode of multidecadal climate variability that causes global climate impacts (e.g., Mantua and Hare 2002; Nidheesh et al. 2017; Zhang et al. 1997). The PDO is characterized by fluctuations in sea surface temperatures (SST) across the Pacific Ocean, with its positive phase exhibiting warm anomalies along the west coast of North America and eastern tropical Pacific and cold anomalies in the central North Pacific.

The PDO is correlated with fluctuations in the rate of change in global mean surface temperature (Trenberth 2015). For example, the period of relatively slow global warming between 1998 and 2014 (Fyfe et al. 2016; Hu and Fedorov 2017)—sometimes referred to as a warming "hiatus" (e.g., Delworth et al. 2015; Huang et al. 2017) — coincided with a transition of the PDO from its positive to negative phase. This phase shift has been identified as an important driver of the "warming hiatus" through increased ocean heat uptake (e.g., Kosaka and Xie 2013; England et al. 2014).

The PDO has traditionally been thought of as an internally generated mode of climate variability, which is a product of the convolution of multiple atmospheric and oceanic processes and feedbacks (Newman et al. 2016; Chen and Wallace 2016;

Supplemental information related to this paper is available at the Journals Online website: https://doi.org/10.1175/JCLI-D-200423.s1.

Corresponding author: William J. Dow, eewjd@leeds.ac.uk
Newman 2007). Specifically, the PDO has been proposed to be a low-frequency, lagged response to El Niño-Southern Oscillation (ENSO) variability (Liu and Alexander 2007; Kim et al. 2014; Newman et al. 2003); however, recent studies have suggested that PDO and ENSO variability are independent phenomena (Wills et al. 2018; Chen and Wallace 2015).

The atmospheric bridge that connects the tropical and North Pacific basins is widely regarded as an important mechanism in governing the spatiotemporal evolution of the PDO (Newman et al. 2003; Schneider and Cornuelle 2005). The posited process (Nidheesh et al. 2017) commences with anomalously warm SSTs in the eastern tropical Pacific, yielding increased rainfall and diabatic heating from enhanced convection. The interaction between the resulting upper-tropospheric divergence and vorticity excites stationary Rossby wave trains that propagate poleward on great circle paths across the North Pacific (Trenberth et al. 1998). These meridionally propagating wave trains cause the Aleutian low-a quasi-stationary low pressure system located near the Aleutian Islands - to strengthen. The enhanced cyclonic circulation is associated with advection of cold, dry air over the western North Pacific and warm moist air along the west coast of North America. The anomalous surface heat fluxes and Ekman transport within the ocean mixed layer combine to cool the central North Pacific and warm the eastern North Pacific, forming the horseshoe-like spatial pattern of SSTs used to define the PDO (Liu and Alexander 2007; Alexander and Scott 2008).

Despite the PDO being widely recognized as an internally generated phenomenon in the climate system, recent studies have suggested that the PDO may be influenced by external forcing. Anthropogenic aerosol emissions have increased in 
East Asia and decreased in North America and Europe over the last 30 years (e.g., Samset et al. 2019; Smith et al. 2011), prompting numerous studies on the effects of changing a heterogeneous pattern of radiative forcing on the global climate system (e.g., Kasoar et al. 2018; Wilcox et al. 2019; Wang et al. 2020; Smith et al. 2016). Smith et al. (2016) examined the transition of the PDO to its negative phase during the aforementioned early twenty-first-century "hiatus" period and concluded, based on results from coupled climate models, that this was driven in part by changes in anthropogenic aerosol emissions over recent decades. They hypothesized that, in response to aerosol forcing over Asia, modulations in the strength of the Walker circulation and excitation of atmospheric Rossby waves caused a weakening of the Aleutian low, inducing a transition to a negative PDO phase through atmosphere-ocean coupling. Other studies have also provided evidence for a causal effect of anthropogenic aerosol emissions on the strength of the Walker circulation and PDO-like SST variability (e.g., Takahashi and Watanabe 2016; Allen et al. 2014; Hua et al. 2018). However, this connection was challenged by Dai et al. (2015) and Oudar et al. (2018), who attributed the early twenty-first-century slowdown in global mean surface temperature trends, and the transition of the PDO to its negative phase, to internal variability. Oudar et al. (2018) analyzed a 50-member initial condition ensemble forced only with anthropogenic aerosol changes and showed a robust local weakening of the Aleutian low (by up to $\sim 0.5 \mathrm{hPa}$ ) between 1998 and 2012 in the ensemble mean; however, they also found nonrobust changes in the PDO and global mean surface temperature trends. These contrasting results exemplify how aerosols continue to be a major source of uncertainty in understanding past and future climate change (Boucher et al. 2013).

Aerosols affect the climate in different ways. The radiative forcing due to aerosol-radiation interactions (RFari in IPCC AR5; Boucher et al. 2013), formerly known as the aerosol direct effect (Charlson et al. 1992), accounts for the interaction of aerosols with radiation before any atmospheric adjustments take place. This is due to aerosols either scattering or absorbing solar radiation. In addition, rapid adjustments induced by aerosol radiative effects on the surface energy budget, the atmospheric profile and cloudiness contribute to the effective radiative forcing from aerosol-radiation interactions (ERFari) - including what was formerly defined as the semidirect effect (Hansen et al. 1997). Interactions between aerosols and clouds (ERFaci), formerly defined as indirect effects, can be separated into either the instantaneous effect on cloud albedo due to changing concentrations of cloud condensation nuclei (RFaci) and the subsequent rapid adjustments to cloud lifetime and thermodynamics (ERFaci). Parameterization of small-scale processes associated with these interactions (e.g., microphysics) carry with them large uncertainties into climate model simulations (e.g., Boucher et al. 2013).

In addition to the uncertainty in the magnitude of direct and indirect aerosols effects, the complex variability in the behavior of different aerosol species, and spatial heterogeneities and uncertainties in the origin and remote influence of aerosols (Smith et al. 2011; Bartlett et al. 2018; Kasoar et al. 2018), conspire to give a low confidence in quantifying the aerosol radiative forcing and wider climate effects (Boucher et al. 2013).
In this study, we aim to better understand the proposed mechanisms for a possible influence of anthropogenic aerosols on the PDO. To this end, we analyze global climate model data from a set of idealized experiments that include large global and regional perturbations of anthropogenic aerosols, as well as data from a linear stationary wave model driven by diabatic heating anomalies to investigate teleconnections to the North Pacific associated with anthropogenic aerosol perturbations. Given that variability in the Aleutian low has been shown to precede variability in the PDO (Smith et al. 2016; Newman et al. 2016), we focus specifically on the impact of aerosol perturbations on the Aleutian low. The manuscript is structured as follows: section 2 describes the methodology and details of the models used. Section 3 compares the results of the global climate model experiments and the linear stationary wave model in the North Pacific. Discussion of the results is provided in section 4 and our conclusions are summarized in section 5 .

\section{Methods}

\section{a. Global climate model simulations}

We analyze climate model simulations from the Precipitation Driver and Response Model Intercomparison Project (PDRMIP; Myhre et al. 2017). All model data are interpolated to a common $2.5^{\circ} \times 2.5^{\circ}$ longitude-latitude grid. The dataset is composed of output from 11 comprehensive climate models that performed a set of idealized aerosol and $\mathrm{CO}_{2}$ perturbation experiments. The control simulation in each model was run with observed year 2000 boundary conditions, including greenhouse gas concentrations, aerosol concentrations or emissions, and orbital parameters; the control simulation in HadGEM2 used preindustrial (year 1860) conditions. Here we analyze the PDRMIP experiments that applied a step increase in anthropogenic aerosols at global and regional scales. The tier 1 PDRMIP experiments include global perturbations of black carbon (BC) and sulfate aerosols, with a 10and 5-times (BCx10 and Sulx5) global instantaneous increase from the baseline state, respectively. Additional experiments performed by a subset of the models (see Table 1) applied a regional tenfold increase in $\mathrm{BC}$ and sulfate over Asia $\left(10^{\circ}-50^{\circ} \mathrm{N}\right.$, $60^{\circ}-140^{\circ} \mathrm{E}$; BCx10a and Sulx10a) and Europe $\left(35^{\circ}-70^{\circ} \mathrm{N}, 10^{\circ} \mathrm{W}-\right.$ $40^{\circ} \mathrm{E}$; Sulx10e), respectively. The multimodel mean (MMM) change in aerosol burden in each experiment, along with the zonal mean burden change for each model, is shown in Fig. 1.

The perturbation experiments were run with two model configurations: 1) with a fully interactive ocean and sea ice models [except CESM1(CAM4) and ECHAM-HAM that used a simplified mixed layer ocean], and 2) with prescribed climatological SSTs and sea ice extent from the control simulation. The two types of simulations were run for at least 100 and 15 years, respectively (see Table 1). Comparisons between these complementary simulations provides an assessment of the sensitivity to the ocean response for each forcing agent. The analysis focuses on years 51-100 from the coupled experiments and all years except the first year in the prescribed SST simulations, which was discarded for spinup. Table 1 contains details of the models and experiments analyzed in the 


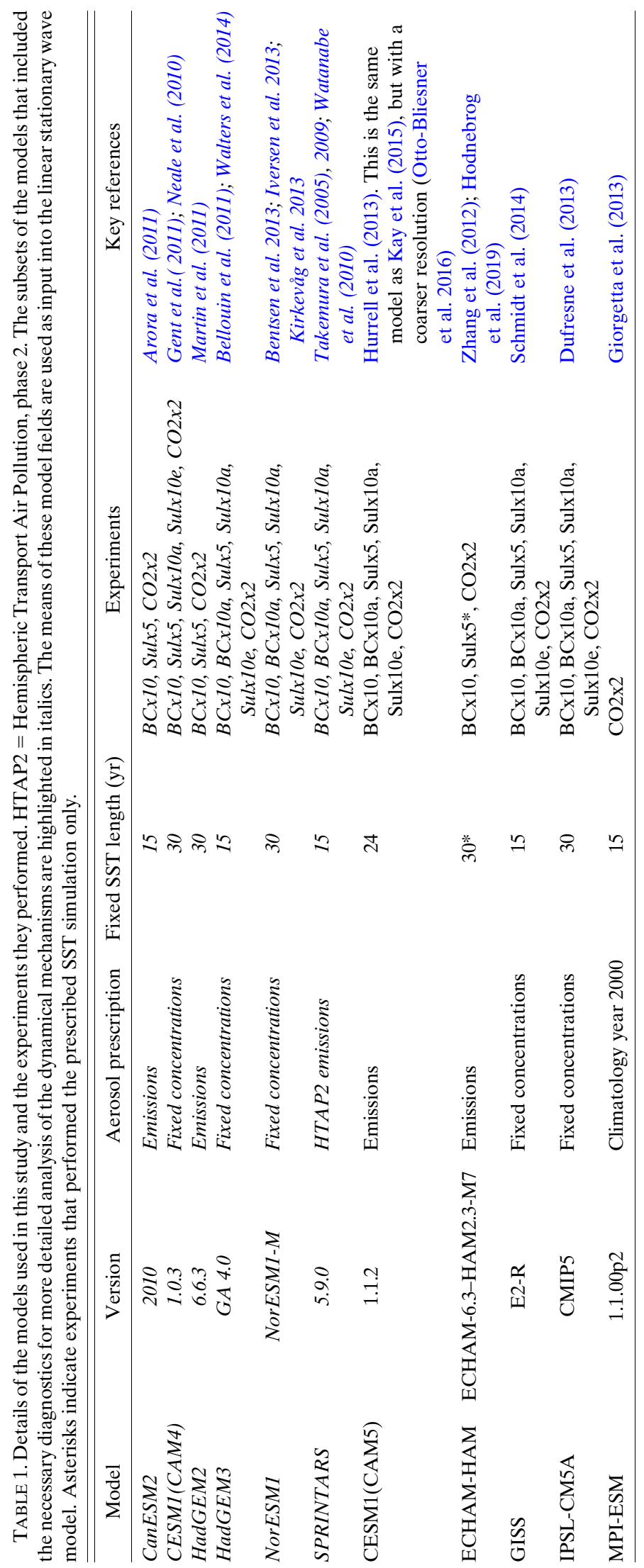




\section{Aerosol burden anomalies - NDJFM}
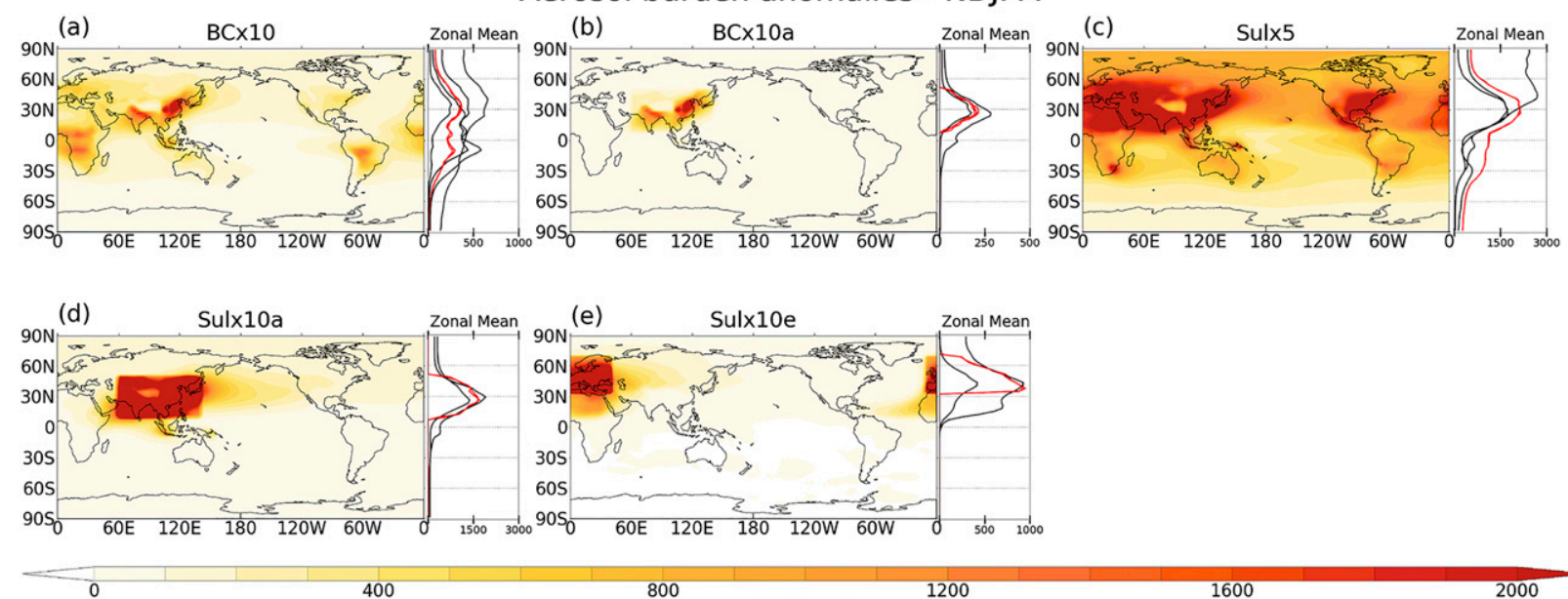

400

800

$x 10^{-7} \mathrm{~kg} \cdot \mathrm{m}^{-2}$

1200

1600

2000

FIG. 1. NDJFM mean MMM aerosol burden anomalies $\left(\times 10^{-7} \mathrm{~kg} \mathrm{~m}^{-2}\right)$ in the (a) BCx10, (b) BCx10a, (c) Sulx5, (d) Sulx10a, and (e) Sulx10e experiments. Side panels show the zonal mean aerosol burden anomalies in individual models; note the different $x$ axis scales. The red lines denote the prescribed aerosol concentration models (identical by construction) and the black lines show models with prescribed emissions (see Table 1).

study. All the analysis presented in the study refers to the extended boreal winter season of November through March (NDJFM) as this is the season when the Aleutian low is most prominent and has been connected to the PDO (Trenberth et al. 2014; Smirnov et al. 2014).

The representation of aerosol processes differs among the models (see Table 1). For models that prescribe aerosol concentrations, a common set of baseline concentration fields were used from phase 2 of the Aerosol Comparisons between Observations and Models (AeroCom) science initiative (Myhre et al. 2017). The remaining models prescribe aerosol emissions and use a detailed aerosol microphysical module to calculate the aerosol burden. Of the 11 models contributing to PDRMIP, indirect effects on clouds from BC and sulfates are included in CanESM2, NorESM1, CESM1(CAM5), Spectral RadiationTransport Model for Aerosol Species (SPRINTARS), and ECHAM-HAM, while IPSL-CM5A incorporates the Twomey effect only. Indirect effects of sulfate but not $\mathrm{BC}$ are included in HadGEM2 and HadGEM3, while CESM1(CAM4) and GISS do not include any indirect effects. MPI-ESM only ran the $\mathrm{CO} 2 \times 2$ experiment. Of the 11 models contributing to PDRMIP, six provided output diagnostics that enabled the analysis of the dynamical mechanisms contributing to the Aleutian low response (i.e., 3D wind fields and geopotential height; see Table 1); the analysis presented in section $3 b$ uses this subset of six models.

\section{b. LUMA}

The Linear University Model of the Atmosphere (LUMA) is a global, stationary wave model that solves the linearized dry, primitive equations on terrain-following sigma levels (Hoskins and Simmons 1975). See Liakka et al. (2012) for a model description and more details on its performance. Here, LUMA is linearized around the MMM extended winter climatology of the PDRMIP control experiments, and the forcing consists of diabatic heating anomalies derived from the PDRMIP perturbation experiments.

For the BC perturbation experiments, we include anomalous heating from both the absorbing aerosol and the anomalous latent heating that forms part of the climate response; both effects can drive planetary Rossby wave trains (Hoskins and Karoly 1981). The direct heating due to the absorbing aerosol is estimated from the PDRMIP MMM BC fields, which are input to the Met Office Suite of Community Radiative Transfer codes (SOCRATES), version 15.04 (based on Edwards and Slingo 1996), using a two-stream delta-Eddington solver. Atmospheric and surface state variables (including clouds and ozone) were used from the ERA5 dataset for the year 2014 (Copernicus Climate Change Service 2017). Optical properties of $\mathrm{BC}$ are used from the HadGEM2 model parameterization, obeying a lognormal size distribution with mean radius $40 \mathrm{~nm}$ and geometric standard deviation of $2.0 \mathrm{~nm}$. No other aerosols are specified in the SOCRATES calculations. Monthly mean shortwave heating rates are calculated using five representative solar zenith angles and Gaussian quadrature. The instantaneous heating rate anomalies derived from SOCRATES are then input to LUMA as an external forcing of the thermodynamic energy equation.

For all experiments, a 3D anomalous latent heating field is estimated following Chan and Nigam (2009) using the MMM mean precipitation anomalies, which are converted to a tropospheric column average heating rate $\left(\mathrm{K} \mathrm{s}^{-1}\right)$ by multiplying by $\left(g L \rho_{w} \times 10^{-5}\right) /\left[C_{p}\left(P_{0}-125\right)\right]$, where $L$ is the latent heat of condensation $\left(2.5 \times 10^{6} \mathrm{~J} \mathrm{~kg}^{-1}\right), g$ is gravity $\left(9.81 \mathrm{~m} \mathrm{~s}^{-2}\right), \rho_{w}$ is the density of water $\left(10^{3} \mathrm{~kg} \mathrm{~m}^{-3}\right), C_{p}$ is the specific heat of air at constant pressure $\left(1004 \mathrm{~J} \mathrm{~kg}^{-1} \mathrm{~K}^{-1}\right)$, and $P_{0}$ is a reference surface pressure calculated from the PDRMIP models. The heating is distributed in the vertical using a Gaussian profile centered at $500 \mathrm{hPa}$ (following Lewinschal et al. 2013). 
Last, the stationary wave response to a given forcing is obtained by inverting a linear operator that is a function of the zonally symmetric background state, and the spectral tendencies of the primitive equations solved sequentially with one spectral wavenumber perturbed by a nonzero value (see details in Liakka et al. 2012). The magnitude of the spectral wavenumber perturbation is an unconstrained parameter (set to order unity in these experiments) that controls the amplitude of the stationary wave response; the spatial patterns of the response are invariant to this parameter. This means that the output from LUMA cannot be quantitatively compared to the PDRMIP results. Thus, while we include color scales in the figures in order to clarify units, we focus on the qualitative comparison of LUMA forced with diabatic heating anomalies and the PDRMIP simulations (cf. Wilcox et al. 2019).

By construction, the LUMA model does not capture all of the processes present in the PDRMIP models. This must be borne in mind when comparing the LUMA results to the PDRMIP models. Nevertheless, this type of model has proven useful in isolating the steady-state stationary wave response to diabatic forcing (e.g., Held et al. 2002), including that due to aerosol perturbations (e.g., Lewinschal et al. 2013; Wilcox et al. 2019), and we therefore use LUMA alongside the PDRMIP models to investigate some of the underlying dynamical mechanisms and teleconnections.

\section{c. Diagnostics}

The North Pacific index (NPI) is defined as the areaaveraged sea level pressure (SLP) anomaly in the region $30^{\circ}-$ $65^{\circ} \mathrm{N}, 160^{\circ} \mathrm{E}-140^{\circ} \mathrm{W}$ (Trenberth and Hurrell 1994).

The Rossby wave source (RWS) is calculated following Sardeshmukh and Hoskins (1988) as

$$
R W S=-\mathbf{v}_{\chi} \cdot \nabla \zeta-\zeta \mathbf{D}
$$

where $\mathbf{v}_{\chi}$ is the divergent component of the horizontal wind, $\zeta$ is the absolute vorticity, and $\mathbf{D}$ is the divergence $\left(\mathbf{D}=\nabla \cdot \mathbf{v}_{\chi}\right)$. The first term represents the rate of change of vorticity due to vorticity advection by the divergent wind, and the second term represents the rate of change of vorticity due to vortex stretching. Although the divergent flow is only a small part of the total horizontal flow, the associated vorticity generation is important for tropicalextratropical interactions. Sardeshmukh and Hoskins (1988) found that a heating near the equator causes a nonlocal vorticity source to emanate in the subtropical westerly jets, which plays a key role for tropical-extratropical teleconnections (Hoskins and Karoly 1981).

Most of the figures in the main text show the PDRMIP MMM responses. To assess the significance of the MMM responses we compare them to the magnitude of internal variability. For each model, at every grid point, variability is calculated by multiplying the standard deviation of overlapping 50-yr means from the control experiments by the square root of 2 . This accounts for the fact that the variability of a difference in means is of interest. This estimates the variation of the difference in standard deviation between two independent averages, which have the same variance, that would be expected due to internal variability. The median value of the standard deviation across the models is used and we show $95 \%$ significance as where the MMM value lies outside of the bounds \pm 1.96 times the standard deviation. This is similar to the method used in IPCC AR5 (2013) to show where a MMM change is large compared to internal variability. Where results from individual models are presented, the statistical significance of the simulated changes with respect to the control simulations is assessed using a two-sided Student's $t$ test $(p<0.05)$.

\section{Results}

\section{a. North Pacific response to global and regional climate perturbations}

Figure 2 shows the near-surface air temperature anomalies over the North Pacific from the coupled perturbation experiments. To compare the aerosol responses to the effect of well-mixed greenhouse gases, we also show results from an instantaneous doubling of carbon dioxide ( $\mathrm{CO} 2 \times 2)$ experiment. The $\mathrm{BC}$ and $\mathrm{CO}_{2}$ perturbations drive global average warming, while the sulfate perturbations drive global cooling. The magnitude of global temperature change varies across the experiments mainly due to different effective radiative forcings induced by each perturbation (Richardson et al. 2019). All the experiments show enhanced temperature changes over land areas and in the Arctic, broadly consistent with the canonical surface temperature response to anthropogenic forcings (e.g., Joshi and Gregory 2008). Interestingly, the BCx10, Sulx10a and, to a lesser extent, the BCx10a show a horseshoe-like pattern of anomalous temperature in the North Pacific that is reminiscent of the $\mathrm{PDO}$. The patterns correspond to a negative PDO-like anomaly for the $\mathrm{BCx} 10$ and $\mathrm{BCx} 10 \mathrm{a}$ experiments, and a positive PDO-like anomaly for Sulx10a.

Figure 3 shows the SLP responses in the experiments; individual model responses in the $\mathrm{BCx} 10, \mathrm{BCx} 10 \mathrm{a}$, Sulx5, and Sulx10a experiments are presented in Figs. S1-S4 in the online supplemental material, respectively. The BCx10 perturbation induces a robust weakening of the Aleutian low (Fig. 3a). The Aleutian low also weakens in the $\mathrm{BCx} 10 \mathrm{a}$ experiment (Fig. 3b), but the magnitude is only about $25 \%$ of the change in $\mathrm{BCx} 10$ and the response is less consistent across models (Fig. S2). Positive SLP anomalies over the North Pacific are only evident in $\sim 50 \%$ of the models for BCx10a, and only CESM1(CAM5) shows a statistically significant response in the North Pacific (Fig. S2). This suggests that sources of BC and associated climate interactions outside of Asia are important contributors to the Aleutian low response in $\mathrm{BCx} 10$.

The SLP response in Sulx5 (Fig. 3c) does not project strongly onto the climatological Aleutian low structure, while the regional sulfate experiments (Sulx10a and Sulx10e; Figs. 3e,f) exhibit a meridional dipole SLP pattern in the North Pacific, with reduced pressure to the south and increased pressure over the Arctic. The SLP response to Sulx5 (Fig. 3c) also displays a significant latitudinal dipole across the North Pacific, with reduced pressure to the west and increased pressure to the east; this pattern of SLP anomalies in the North Pacific is broadly 


\section{Near surface temperature anomalies}

(a)

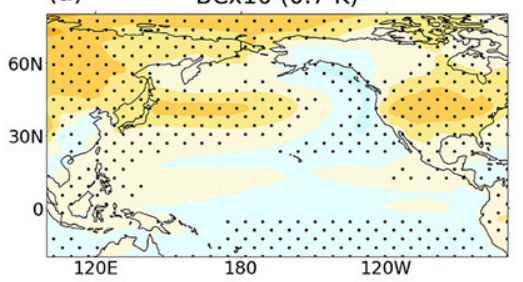

(d)

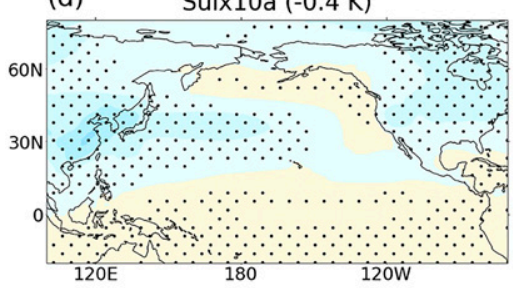

(b)

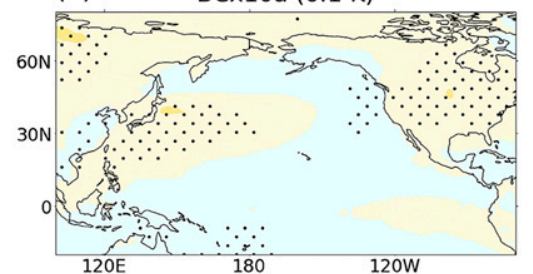

(e)

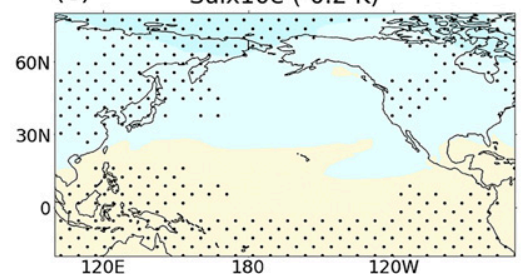

(c)

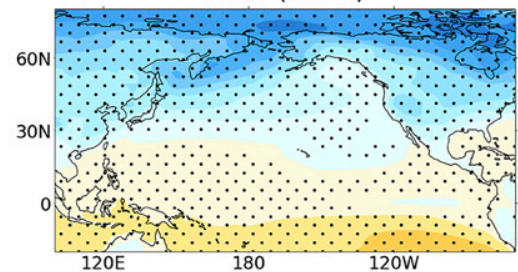

(f)

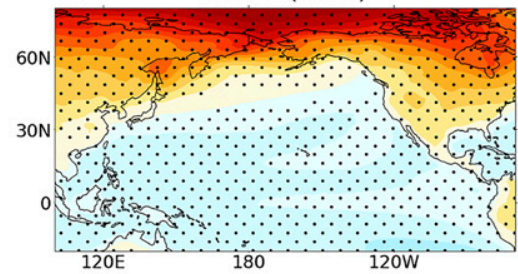

$-5.0$

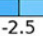

Temperature (K)

FIG. 2. MMM annual mean surface air temperature (K) anomalies in the six coupled perturbation experiments. Stippling indicates differences that are significant at the $95 \%$ confidence level (see section 2 ). The global mean surface temperature change in each experiment (see headers) has been subtracted to highlight the regional patterns.

similar to that found by Qin et al. (2020) when assessing the surface patterns associated with aerosol forcing over the historical period. There is agreement across models that SLP increases in the Arctic in response to Sulx5 and Sulx10a. The $\mathrm{CO} 2 \mathrm{x} 2$ experiment shows a comparatively small increase in SLP over part of the Aleutian low sector; however, the largest changes occur in the Arctic, where there are stronger negative SLP anomalies (Fig. 3f) though not all of the models show this pattern. We note that in general for these experiments, the pattern and magnitude of the North Pacific SLP anomalies in the subset of six models that provided 3D output variables are similar to those for the full set of models (Fig. S5).

\section{Sea Level Pressure Anomalies - NDJFM}

(a)

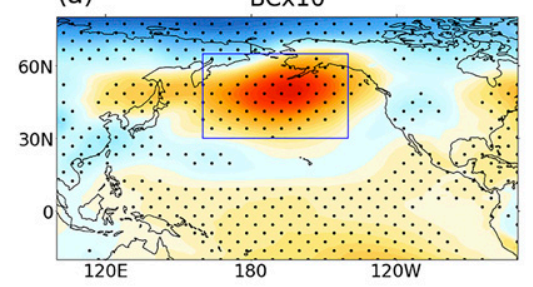

(d)

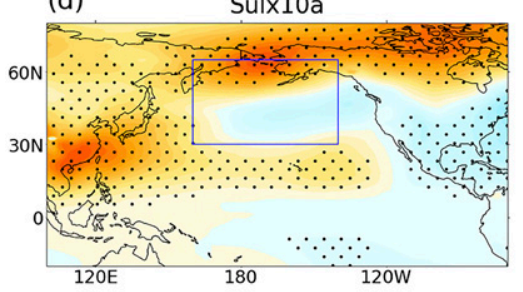

(b)

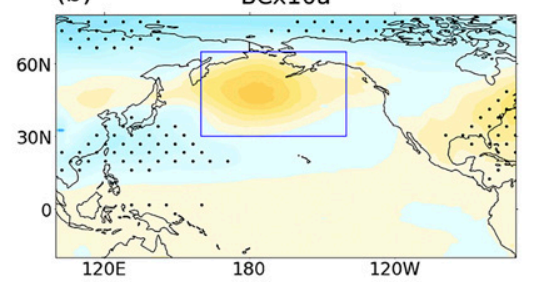

(e)

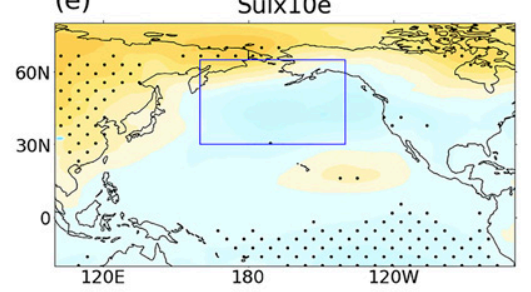

(c)

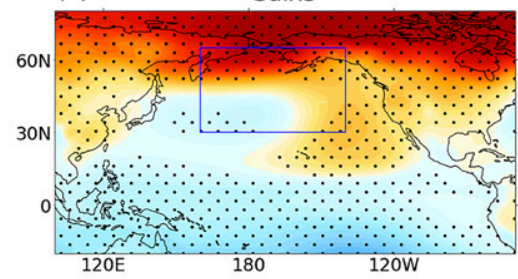

(f)

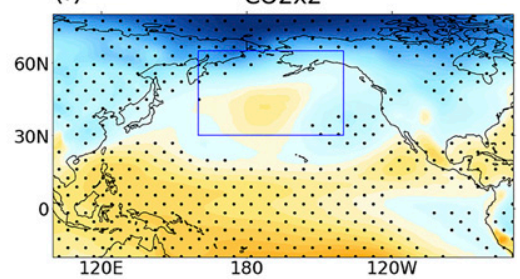

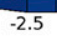

$-2.0$

$-1.5$

$-1.0$

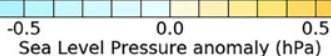

FIG. 3. MMM NDJFM sea level pressure (hPa) anomalies in the coupled perturbation experiments: (a) BCx10, (b) BCx10a, (c) Sulx5, (d) Sulx10a, (e) Sulx10e, and (f) CO2x2. Stippling indicates differences that are significant at the $95 \%$ confidence level. The box is the region used to define the NPI. 


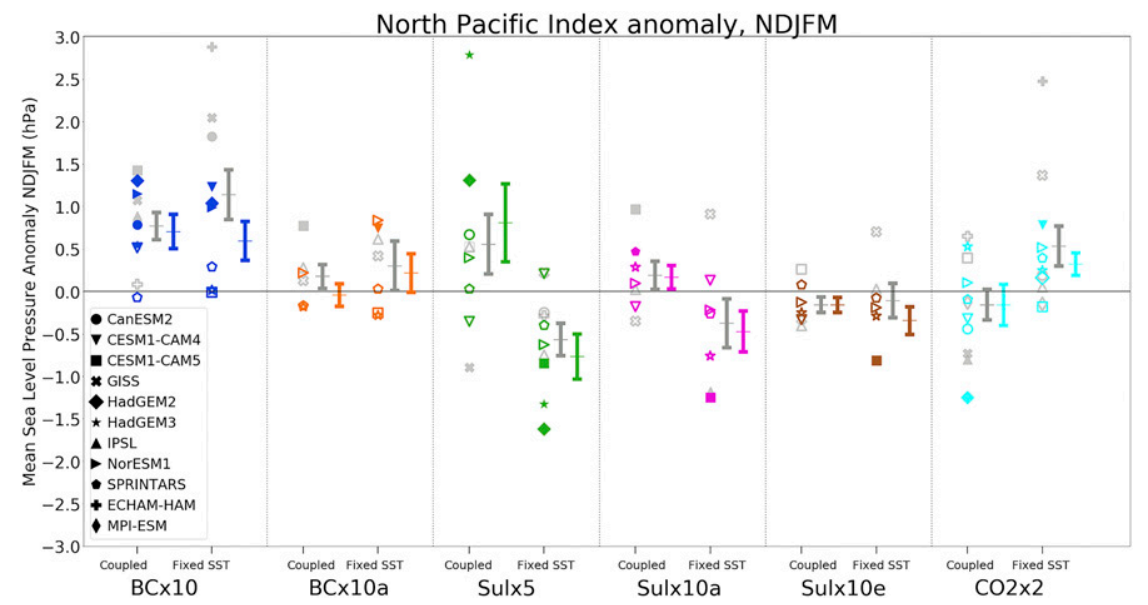

FIG. 4. The NPI anomaly (averaged over $\left.30^{\circ}-65^{\circ} \mathrm{N}, 160^{\circ} \mathrm{E}-140^{\circ} \mathrm{W}\right)(\mathrm{hPa})$ averaged for NDJFM. For each experiment (column), values are shown for coupled (average years 51-100; left) and prescribed (fixed) SST experiments (average after year 1; right). Colored symbols show the model subsets used to create input fields for LUMA, with gray symbols showing other models. Filled symbols represent differences that are significant at the $95 \%$ confidence level, and vice versa for open symbols. The line-and-whisker symbols show the MMM \pm 1 standard error for each experiment.

The NPI anomalies for individual models in both the coupled and prescribed SST experiments are shown in Fig. 4. A comparison between the coupled and prescribed SST experiments enables an assessment of the role of atmosphere-ocean coupling for the long-term NPI response to each perturbation. The North Pacific spatial SLP anomalies in the prescribed SST experiments are shown in Fig. S6 for reference. For BCx10, seven out of ten models show a significant increase in the NPI; we find no discernable difference in NPI response between the fully coupled (left column) and prescribed SST (right column) simulations, implying that atmosphere-ocean coupling plays only a relatively small role for the NPI response to BCx10. In $\mathrm{BCx} 10 \mathrm{a}$, the NPI response is weaker and generally less significant in the models, though the MMM anomaly is positive and around $25 \%$ of the magnitude in $\mathrm{BCx} 10$.

The intermodel spread is largest in the coupled Sulx5 experiment, where two models out of nine show a significant increase in NPI, one shows a significant decrease and six show no significant change from the control experiment. The coupled MMM response to Sulx10a shows a small increase in the NPI, which is qualitatively consistent with the weakening of the Aleutian low identified by Smith et al. (2016) and Oudar et al. (2018). However, only two out of seven models for Sulx10a show an NPI response that is significant relative to internal variability. Furthermore, the pattern of SLP anomalies in Sulx10a does not strongly resemble the climatological Aleutian low, with the NPI area average reflecting a cancellation of opposite sign anomalies between the southern and northern parts of the region (Fig. 3d). Interestingly, both Sulx5 and Sulx10a show an opposite sign of NPI response between the prescribed SST and coupled simulations, with a clear shift in the distribution of models from generally negative to positive NPI anomalies. The CO2x2 experiment also exhibits a similar behavior but in the opposite sense, suggesting that the ocean plays an important role in the long-term Aleutian low response to sulfate and $\mathrm{CO}_{2}$ forcing. Since these forcings induce larger surface temperature changes than BC (Fig. 2), this suggests the NPI response is mediated by surface-temperaturedriven feedbacks. Last, we note that in every experiment there is substantial intermodel spread in the NPI response, with at least one model having an opposite sign of response to the MMM.

\section{b. Mechanistic explanation of the Aleutian low response to aerosols}

This section investigates the dynamical mechanisms that underpin the Aleutian low responses discussed in section 3a. We focus here on the coupled model experiments that isolate the effects of global and Asian aerosol forcing: BCx10, BCx10a, Sulx5, and Sulx10a.

\section{1) UPPER-TROPOSPHERIC GEOPOTENTIAL HEIGHT RESPONSES}

The $300 \mathrm{hPa}$ eddy geopotential height anomalies in the four selected aerosol perturbation experiments are shown in Fig. 5. In BCx10 (Fig. 5a), across the North Pacific sector, there is an anomalous ridge with two local maxima of around $25-30 \mathrm{~m}$ over China and in the North Pacific and an anomalous trough of around 15-20 m centered off the west coast of North America. Comparison with the surface response (Fig. 3a) shows a westward tilt that resembles the vertical structure of stationary Rossby waves. In the $\mathrm{BCx} 10 \mathrm{a}$ experiment, the anomalous uppertropospheric ridge over China is weaker $(\sim 10 \mathrm{~m})$ and located farther south than in $\mathrm{BCx} 10$. This suggests that remote $\mathrm{BC}$ aerosols are contributing substantially to the ridge over China in BCx10. Within the North Pacific region itself, there is an anomalous ridge with a local maximum of $\sim 10 \mathrm{~m}$ on the western side of the basin, and a trough with a similar amplitude to the east in BCx10a. These midlatitude anomalies are weaker and shifted westward by around $20^{\circ}$ compared to BCx10. In Sulx 5, there is a ridge with local maximum of around $20 \mathrm{~m}$ extending across the 
300hPa eddy geopotential height anomalies - NDJFM
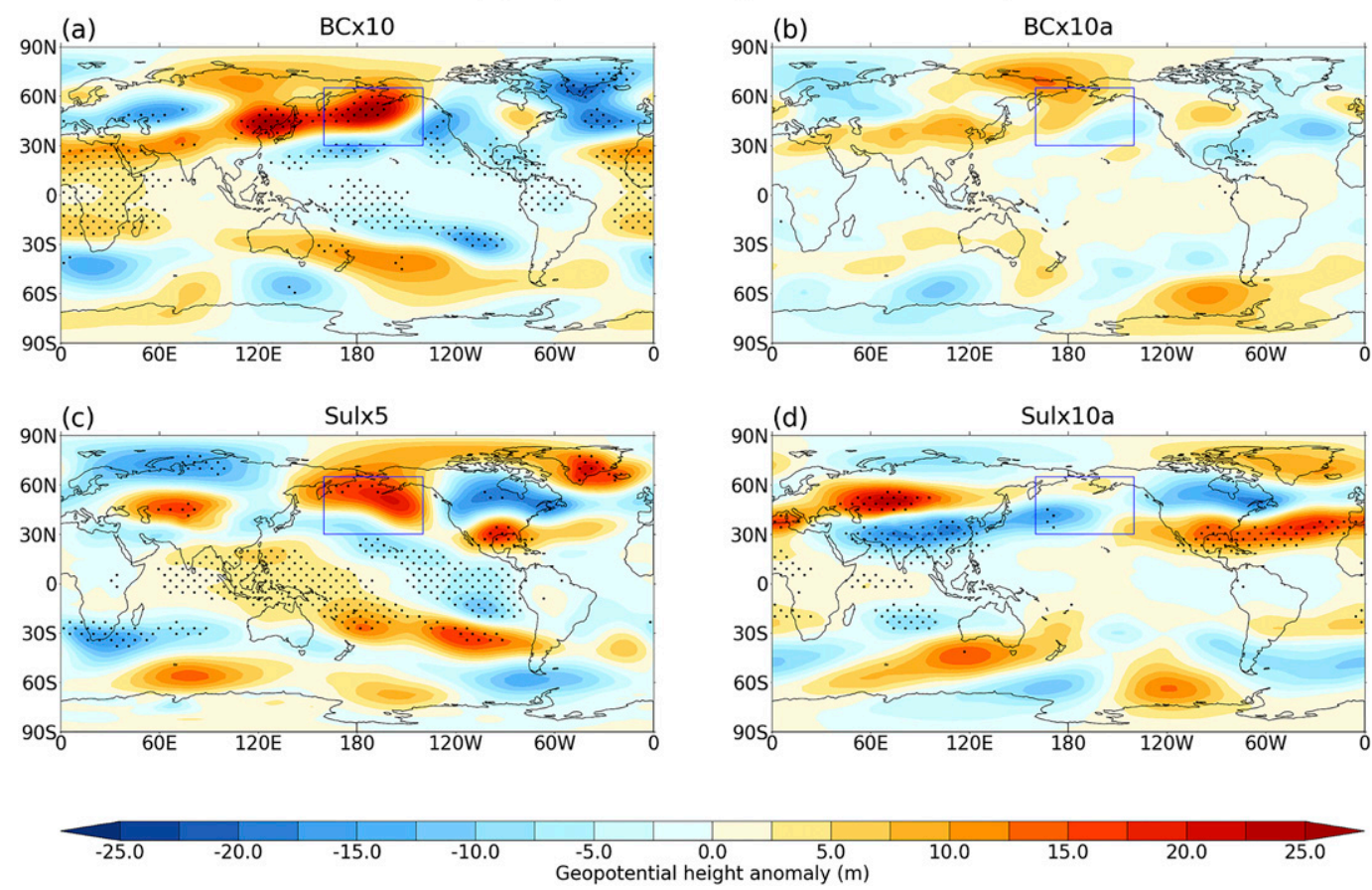

FIG. 5. MMM NDJFM $300 \mathrm{hPa}$ eddy geopotential height (m) anomalies in the (a) BCx10, (b) BCx10a, (c) Sulx5, and (d) Sulx10a experiments. The MMM is constructed using the subset of models that provided 3D output variables used as inputs to LUMA (see Table 1). Stippling indicates differences that are significant at the $95 \%$ confidence level. The box is the region used to define the NPI.

North Pacific sector, a trough with a local maximum of around $10 \mathrm{~m}$ to the south, and downstream a reversal in the meridional pattern with a trough over the northern United States (local maximum $\sim 20 \mathrm{~m}$ ), and a ridge with similar amplitude over the southern United States. The midlatitude response to sulfate aerosols is generally more baroclinic than for BC aerosol. For example, in both Sulx5 and Sulx10a there is a trough in the upper troposphere over the northern United States and Canada, whereas at the surface the experiments show a ridge in this region.

\section{2) Rossby wave SOURCE RESPONSES}

Figure 6 shows the anomalous RWS [Eq. (2)] in the four aerosol perturbation experiments. The RWS represents anomalous sources and sinks of vorticity, which can induce meridionally propagating Rossby wave trains (e.g., Hoskins and Karoly 1981; Sardeshmukh and Hoskins 1988). Smith et al. (2016) found that anthropogenic aerosols caused a negative trend in RWS east of Japan between 1998 and 2012 (their Fig. S9). They proposed that Rossby waves emanating from this region propagate northeastward across the North Pacific, and thereby weaken the Aleutian low.

Figure 6d shows that in the Sulx10a experiment there is a positive RWS anomaly east of Japan-which is opposite in sign to the anomaly highlighted by Smith et al. (2016) — but the largest positive RWS anomalies occur farther upstream in central China. In Sulx5, the RWS anomaly to the east of Japan has the opposite sign (Fig. 6c), suggesting that the response to local forcing from Asian aerosols is overwhelmed by the response to aerosols outside of this region. Large RWS anomalies across the northern extratropics suggest that remote sources may also help influence the circulation response over the North Pacific region. The BCx10a experiment shows dipole RWS anomalies upstream of the North Pacific over eastern China and Russia, with a positive anomaly around $45^{\circ}-60^{\circ} \mathrm{N}$ and a negative anomaly around $30^{\circ}-45^{\circ} \mathrm{N}$ (Fig. $6 \mathrm{~b}$ ). The negative node of this pattern is present in $\mathrm{BCx} 10$ but is around twice the magnitude and extends farther east out over Japan and into the North Pacific sector (Fig. 6a). In addition, the BCx10 experiment demonstrates a positive RWS node farther downstream in the central-eastern North Pacific, around $30^{\circ}-45^{\circ} \mathrm{N}$, which extends northeast over northwest Canada. This represents the second major node visible across the North Pacific, not apparent in the BCx10a experiment, and suggests sources of BC outside of Asia affect North Pacific tropospheric dynamics. Further analysis (not shown) indicates that for all experiments the anomalous RWS in the northern extratropics is predominantly caused by changes in upper-level divergence rather than by changes in the meridional gradient in absolute vorticity.

\section{3) PRECIPITATION RESPONSES}

The precipitation responses (Fig. 7) in the PDRMIP simulations, and their driving mechanisms, have been described in 
RWS anomalies - NDJFM
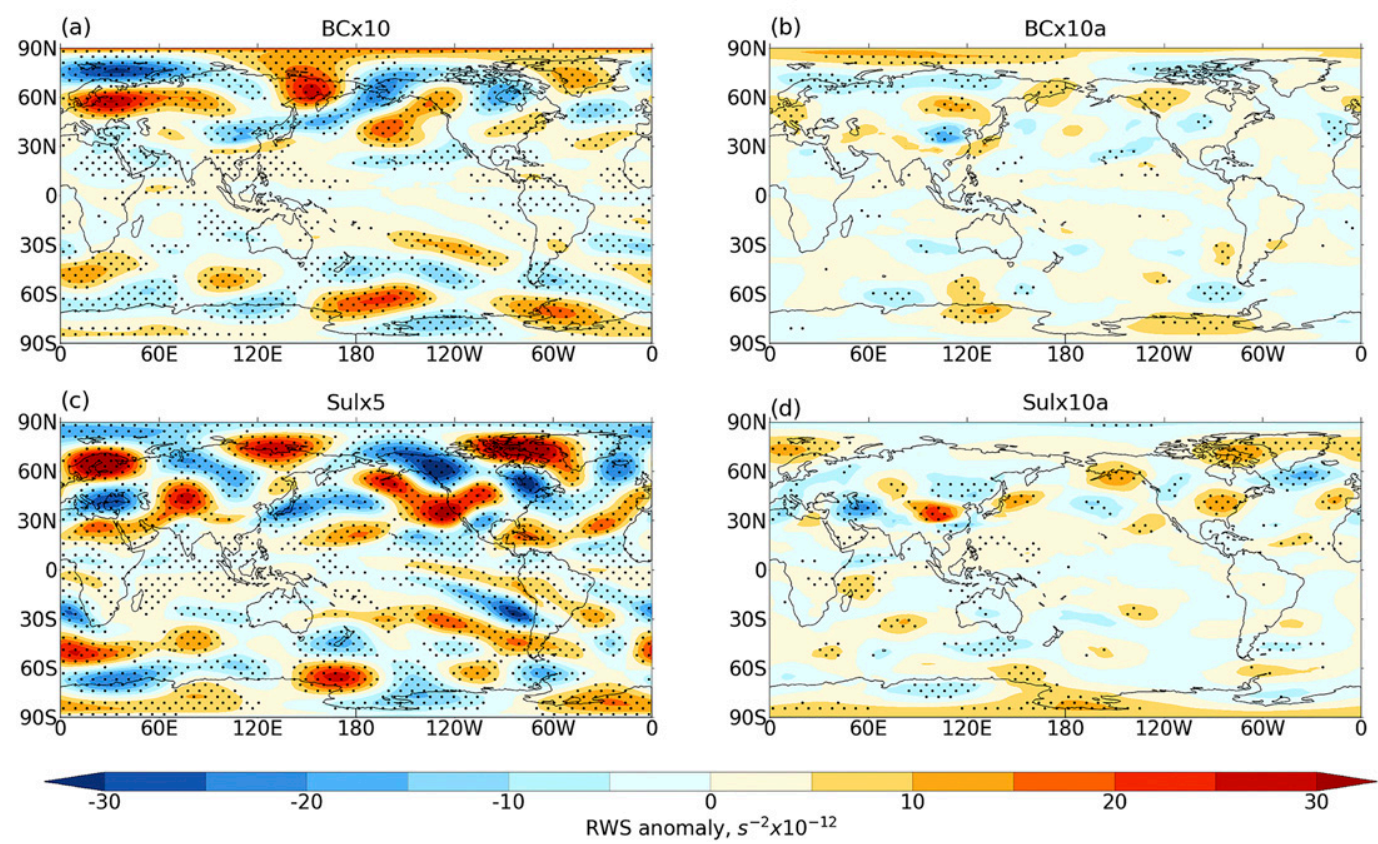

FIG. 6. NDJFM RWS $\left(\times 10^{-12} \mathrm{~s}^{-2}\right)$ anomalies in the coupled experiments, calculated using the NDJFM MMM zonal and meridional wind fields. The $\mathrm{BCx} 10$ and Sulx 5 responses are scaled by $0.5 \times$ for display purposes. Stippling indicates differences that are significant at the $95 \%$ confidence level.

detail in, for example, Samset et al. (2016), Liu et al. (2018), and Richardson et al. (2018). Here we briefly summarize the key changes in precipitation that are relevant for interpreting the Aleutian low response to the aerosol perturbations and the role of teleconnections in the response. $\mathrm{BCx} 10$ and the two sulfate perturbation experiments show a reduction in global mean precipitation, with Sulx 5 showing the largest decrease of $\sim 0.2 \mathrm{~mm} \mathrm{day}^{-1}(-7 \%)$. BCx10 shows increased precipitation at high northern latitudes and decreases across the northern midlatitudes. Tropical precipitation is substantially reduced (by $\sim 1 \mathrm{~mm} \mathrm{day}^{-1}$, equivalent to a $14 \%$ local reduction) in Central and South America, as well as in the equatorial Indian Ocean, indicating a northward shift of the intertropical convergence zone (ITCZ) away from the cooler hemisphere (cf. Kang et al. 2008). In the southern extratropics, there is a dipole pattern of precipitation change that is associated with a poleward shift of the Southern Hemisphere storm track (Wood et al. 2020). BCx10a shows a near-zero change in global precipitation, which suggests that regions of net increased and decreased precipitation are of comparable magnitude. Regional precipitation changes are weaker and less robust in $\mathrm{BCx} 10 \mathrm{a}$, but there is a coherent decrease in the tropical Indian Ocean by $0.2-0.4 \mathrm{~mm} \mathrm{day}^{-1}$ ( $-3 \%$ local reduction).

In Sulx 5 the regional precipitation changes are generally larger and more robust across the models. There are reductions in precipitation across the northern and southern high latitudes, over India, southeast China, and in the Indian Ocean, in the equatorial Pacific indicating a southward shift of the ITCZ, and in the North Pacific, with local anomalies exceeding
$2 \mathrm{~mm} \mathrm{day}^{-1}$ (up to $-32 \%$ of the local mean). In Sulx10a, there is increased precipitation across Africa, the Middle East, and the western Indian Ocean, and decreased precipitation over India, China, and in the northern subtropics and the North Pacific. The precipitation anomalies in Sulx10a reach up to around $\pm 1.5 \mathrm{~mm}$ day $^{-1}$ locally, with significant reductions in precipitation over Asia and into the North Pacific caused by a combination of factors including a weakening monsoon circulation, a decrease in surface temperature over the North Pacific, and a southward shift of the ITCZ (Liu et al. 2018). Note there is generally greater intermodel spread in the precipitation responses to $\mathrm{BC}$ as compared to the sulfate perturbations, as indicated by the smaller amount of stippling in Fig. 7.

\section{4) LUMA}

To further investigate the mechanisms for the North Pacific responses to aerosol forcing, we run LUMA (section $2 b$ ) with diabatic heating anomalies derived for the absorbing $\mathrm{BC}$ aerosol and precipitation anomalies induced by the different aerosol species. Figure S7 shows the pattern of heating rate anomalies due to the $\mathrm{BCx} 10$ absorption calculated in the SOCRATES radiative transfer model. The anomalous heating rates (up to $1 \mathrm{~K} \mathrm{day}^{-1}$ ) driven by $\mathrm{BC}$ absorption are largely confined to pressures greater than $500 \mathrm{hPa}$, closely following the distribution of $\mathrm{BC}$ burden (Fig. 1). In addition, the precipitation anomalies in Fig. 7 are used to estimate a 3D distribution of anomalous latent heating for all experiments (see details in section 2). We further investigate how the North 


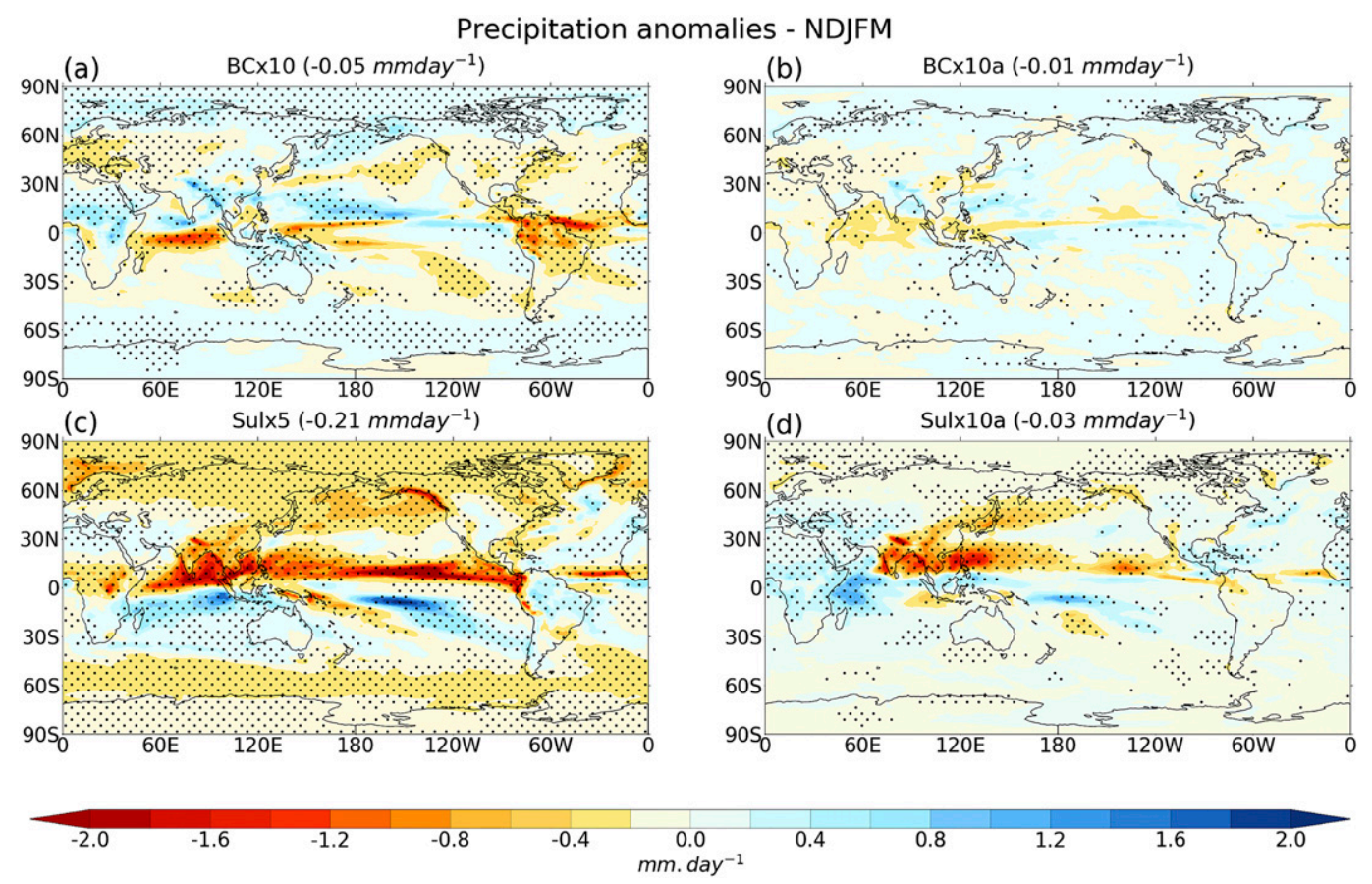

FIG. 7. NDJFM mean MMM precipitation $\left(\mathrm{mm} \mathrm{day}^{-1}\right)$ anomalies in four coupled aerosol perturbation experiments. Stippling indicates differences that are significant at the $95 \%$ confidence level. The global average precipitation anomaly is given in parentheses.

Pacific stationary wave response is influenced by diabatic heating anomalies in different regions.

For comparison with the upper-tropospheric responses at $300 \mathrm{hPa}$ in the PDRMIP models, we show results from LUMA at $\sigma=0.35$. The upper-tropospheric circulation responses in the linear model are presented in Fig. 8. BCx10 heating causes the largest anomalous divergence at low latitudes, with enhanced divergence over the equatorial Indian Ocean, the Philippines, and the tropical Pacific as well as over China (Fig. 8a). Conversely, anomalous convergence is present along the equator in the Pacific and northern South America. The largest increases in geopotential height are located over China, extending in a southwest-northeast-tilted pattern from India across the North Pacific to northern Canada. This response is predominantly driven by the direct radiative heating from the absorbing aerosol (not shown). The pattern of geopotential height anomalies over China and the North Pacific qualitatively resembles the PDRMIP response in Fig. 5a; however, the upper-level ridge near the Aleutian Islands is similar in magnitude to over eastern China in PDRMIP, while in LUMA it is proportionately weaker suggesting the stationary wave model is missing a process that amplifies the North Pacific ridge.

Similarly, the anomalous meridional winds in LUMA show a wave train emanating from central China and propagating northeastward toward the North Pacific and Arctic (Fig. 8b). There is also a wave train emanating from central China that propagates southeastward toward the equatorial Pacific. The zonal wind anomalies show a poleward shift in the uppertropospheric North Pacific jet maximum near Japan (cf.
Johnson et al. 2019), and a weakening near the jet exit region farther downstream (Fig. 8d).

To further explore the importance of local and remote BC forcing on the North Pacific upper-tropospheric circulation, Fig. 9 shows geopotential height anomalies resulting from regional heating applied over China, equatorial Africa, Indonesia, and Nepal/India. These regions represent areas with the largest radiative heating from the BC absorption (Fig. S7). The majority of the geopotential height increase over China and India is associated with local heating anomalies. Both regional forcings excite Rossby wave trains that propagate downstream in a northeasterly direction (Figs. S8a-d) and project onto an increase in geopotential height near $60^{\circ} \mathrm{N}$ in the North Pacific and a decrease near $30^{\circ} \mathrm{N}$, thereby contributing to the overall North Pacific response in Fig. 8b. Conversely, localized heating over equatorial Africa and Indonesia have a negligible impact on circulation in the North Pacific, only inducing local wave trains (Figs. S8b,c). However, these four regions do not explain the full linear response to the global heating anomaly in BCx10. Figure 10a shows the sum of the geopotential responses for the four regions and Fig. 10b shows the difference between the total response (Fig. 8a) and this sum. This residual shows that heating outside of China, India, equatorial Africa, and Indonesia drives increased geopotential height over Japan.

Figure 11 shows the meridional wind and geopotential height anomalies diagnosed from the linear model for Sulx5, Sulx10a, and BCx10a. The linear model does not reproduce the PDRMIP MMM response over the North Pacific in Sulx5 


\section{LUMA output for BCx10 global heating $-\sigma=0.35$}
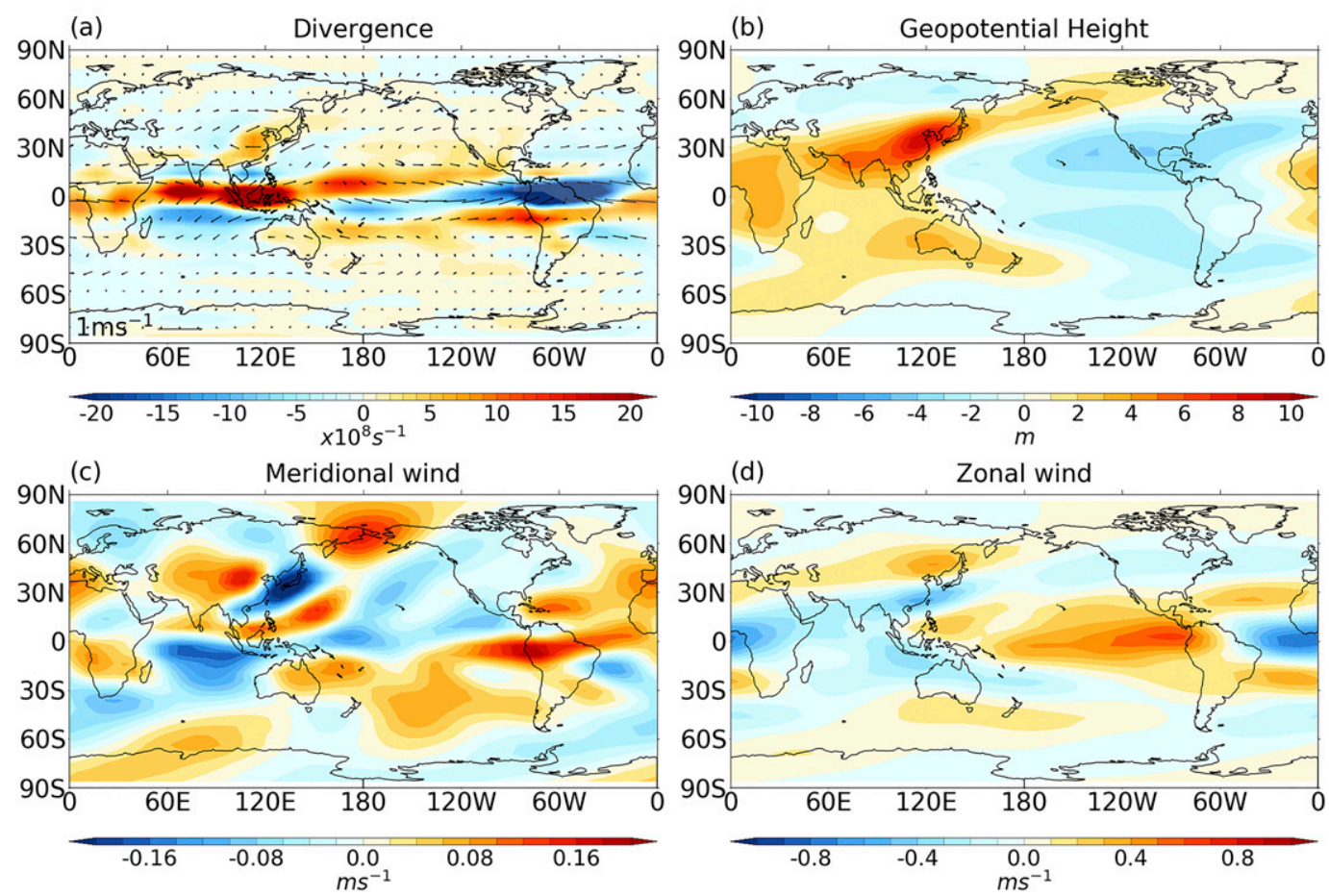

FIG. 8. LUMA steady-state response $(\sigma=0.35)$ to diabatic heating anomalies from the NDJFM global atmospheric absorption and precipitation for the BCx10 experiment: (a) divergence $\left(\mathrm{s}^{-1}\right),(\mathrm{b})$ geopotential height $(\mathrm{m})$, (c) meridional wind $\left(\mathrm{m} \mathrm{s}^{-1}\right)$, and (d) zonal wind $\left(\mathrm{m} \mathrm{s}^{-1}\right)$. Wind vectors are also shown in (a).

(Figs. 11a,b). It does, however, reproduce the height anomalies over North America. We note that precipitation anomalies north of $45^{\circ} \mathrm{N}$ contribute to the split trough over northwest North America, where we see a local geopotential height minimum of around $-2 \mathrm{~m}$. In contrast, the PDRMIP pattern of response to Sulx10a is relatively well captured by the linear model (cf. Fig. 5 and Figs. 11c,d). The precipitation anomalies over China and Nepal/India generate a trough over continental Asia. Further sensitivity simulations reveal that the trough around $25^{\circ} \mathrm{N}$ extending northeast over the North Pacific is excited by precipitation anomalies over China and Nepal/India (Fig. S9). Heating from remote regions, such as Africa, the western and eastern Indian Ocean, and the equatorial Pacific Ocean have a smaller influence on the circulation changes in the North Pacific, but in combination, deepen the trough over Asia (Fig. S10). Latent heat anomalies north of $45^{\circ} \mathrm{N}$ affect the anomalies in the Sulx10a experiment by broadening and enhancing the trough over the North Pacific (not shown). Heating from precipitation anomalies over Nepal/India compound the ridge over the subtropical east Pacific near $25^{\circ} \mathrm{N}$, with its effect extending downstream over the Atlantic Ocean (not shown).

The linear response to the combined aerosol and latent heating for BCx10a broadly resembles the PDRMIP MMM over the North Pacific (cf. Fig. 5b and Figs. 11e,f), though with a more pronounced southwest-northeast tilt of the ridge-trough pattern. Moreover, the response to $\mathrm{BCx} 10 \mathrm{a}$ is structurally similar to that for $\mathrm{BCx} 10$. The majority of the North Pacific response to both $\mathrm{BCx} 10$ and $\mathrm{BCx} 10 \mathrm{a}$ is due to aerosol heating over India and China, with a comparatively smaller contribution from latent heating.

\section{Discussion}

Smith et al. (2016) found that models participating in phase 5 of the Coupled Model Intercomparison Project (CMIP5) simulated a weakening of the Aleutian low over the period 1998-2012 in response to a transient increase in anthropogenic aerosol emissions from East Asia. This weakening corresponded to an increase in SLP in the North Pacific over the 15yr period of up to $0.75-0.9 \mathrm{hPa}$. Caution should be taken when comparing the long-term centennial response in the PDRMIP coupled experiments with the decadal trends considered by Smith et al. (2016), particularly given the idealized, large step increases in aerosol applied here, which are strongly contrasting with the observed reduction in emissions over Europe and North America and concurrent increase over Asia in the past few decades (Smith et al. 2016). We find that the sign of the NPI response to a step sulfate aerosol forcing changes between the prescribed SST and coupled experiments and the decadal response falls somewhere between these two time scales (i.e., transient rather than equilibrium). Furthermore, the pattern of aerosol forcing in Sulx10a (Fig. 1) is different from that 
LUMA - geopotential height output for $\mathrm{BC} \times 10$ regional heating $-\sigma=0.35$
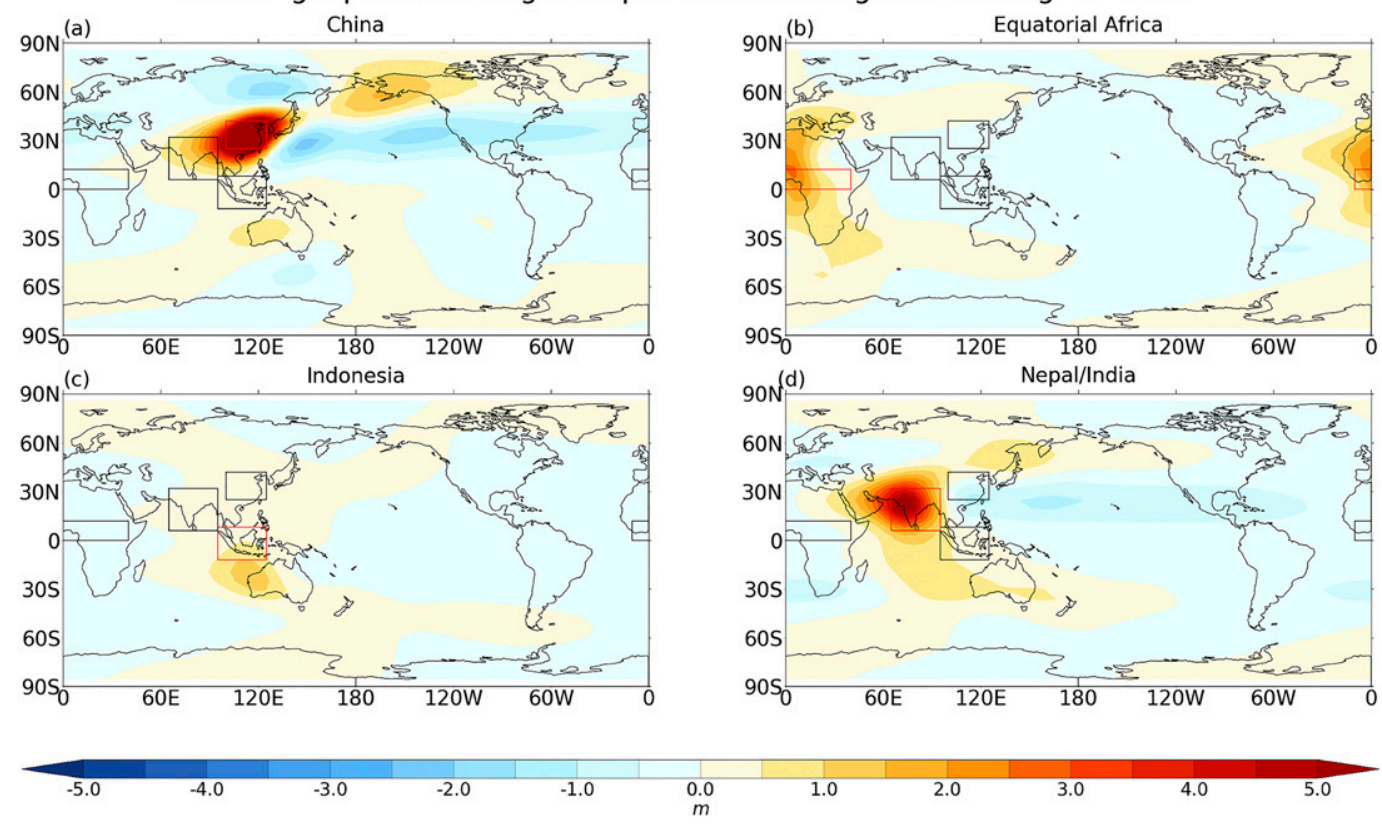

FIG. 9. LUMA steady-state NDJFM geopotential height $(\mathrm{m})$ anomalies $(\sigma=0.35)$ due to regional diabatic heating from the $\mathrm{BCx} 10$ experiment. The regions, defined by areas with the largest radiative heating from $\mathrm{BC}$ absorption (Fig. S7), are (a) China $\left(25^{\circ}-42^{\circ} \mathrm{N}, 100^{\circ}-125^{\circ} \mathrm{E}\right)$, (b) equatorial Africa $\left(0^{\circ}-12^{\circ} \mathrm{N}, 10^{\circ} \mathrm{W}-40^{\circ} \mathrm{E}\right)$, (c) Indonesia $\left(12^{\circ} \mathrm{S}-8^{\circ} \mathrm{N}, 95^{\circ}-125^{\circ} \mathrm{E}\right)$, and (d) Nepal/India $\left(6^{\circ}-32^{\circ} \mathrm{N}, 65^{\circ}-95^{\circ} \mathrm{E}\right)$.

observed in recent decades (Samset et al. 2019). Nevertheless, the multimodel mean NPI anomaly in the Sulx10a experiment is only $0.2 \mathrm{hPa}$, which is considerably weaker than the change identified by Smith et al. (2016) despite the regional aerosol perturbation in Sulx10a being many times larger than the trend over 1998-2012. Only CESM1(CAM5) produces an NPI anomaly in the coupled experiments with a comparable magnitude to the changes found by Smith et al. (2016).

Oudar et al. (2018) used the CanESM5 model to investigate drivers of Aleutian low trends over the same period as Smith et al. (2016). They showed that a 50-member historical ensemble including only anthropogenic aerosol forcing produced a weakening of the Aleutian low over 1998-2012 by up to around $0.45-0.5 \mathrm{hPa}$ locally, but this had no robust effect on the PDO or global mean surface temperature trends. One of the contributing models to PDRMIP is CanESM2, a predecessor version of the Canadian Earth System Model. CanESM2 did not perform the Sulx10a experiment, but in the Sulx5 experiment the model does show an increased NPI by $0.7 \mathrm{hPa}$ that is consistent with a weakening of the Aleutian low.

LUMA - geopotential height output for $\mathrm{BC} \times 10$ regions $-\sigma=0.35$
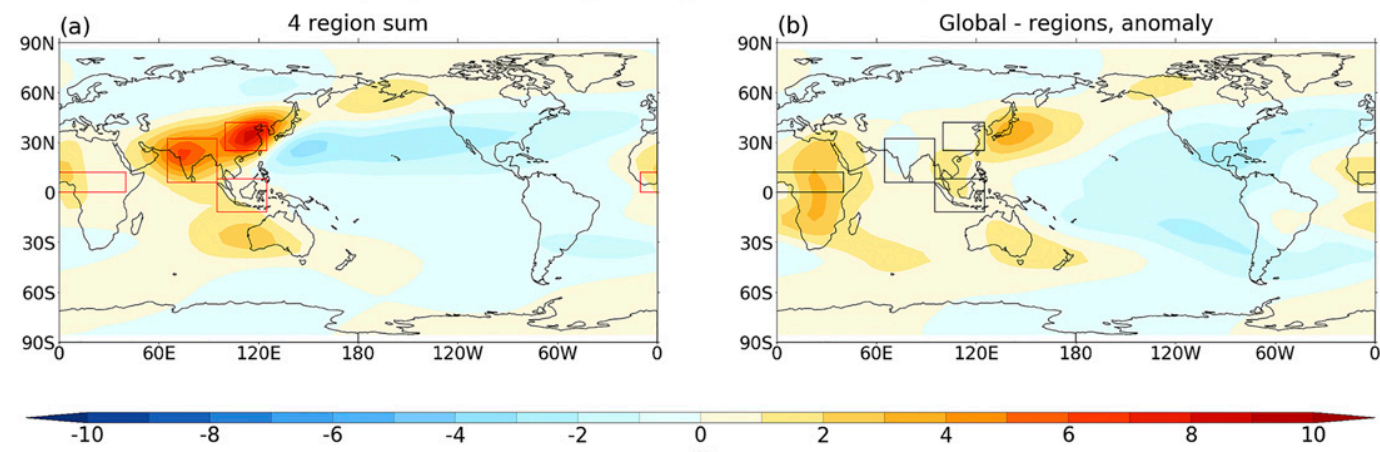

$$
-2
$$

\section{0}

FIG. 10. LUMA steady-state NDJFM geopotential height anomalies $(\sigma=0.35)$ due to diabatic heating from the BCx10 experiment. (a) Sum of responses to the four regions shown in Fig. 9 (China, equatorial Africa, Indonesia, and Nepal/India). (b) Difference between the response to the global diabatic heating field in Fig. $8 \mathrm{~b}$ and the sum of the four subregions in (a). 
LUMA - meridional wind and geopotential height output for Sulx5, Sulx10a, BCx10a - $\sigma=0.35$
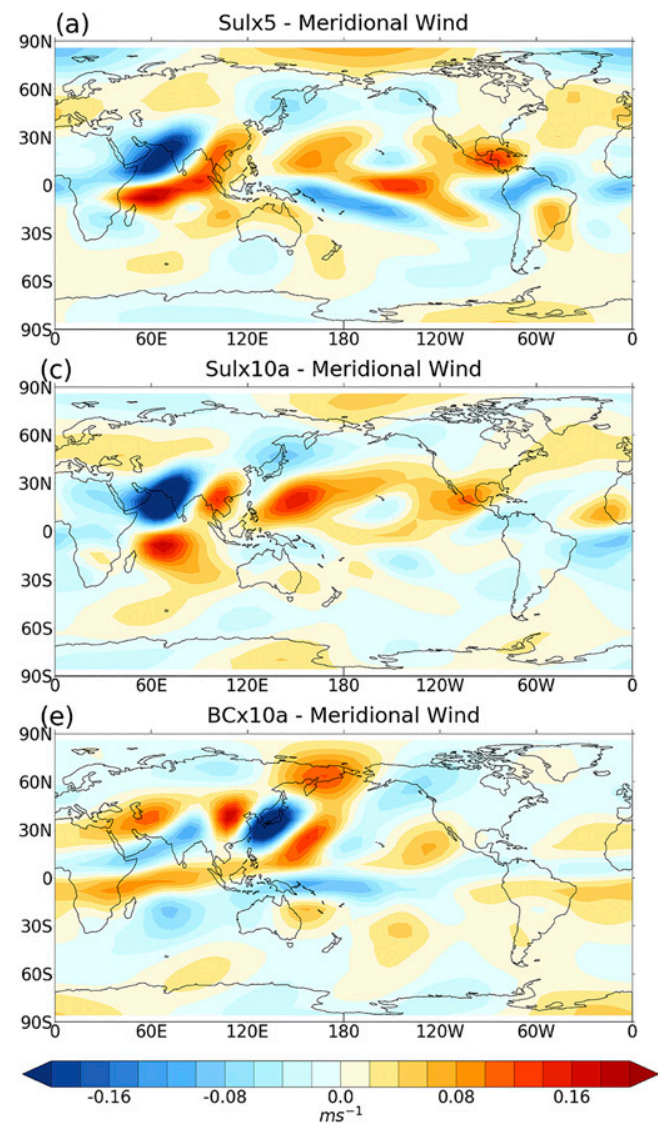
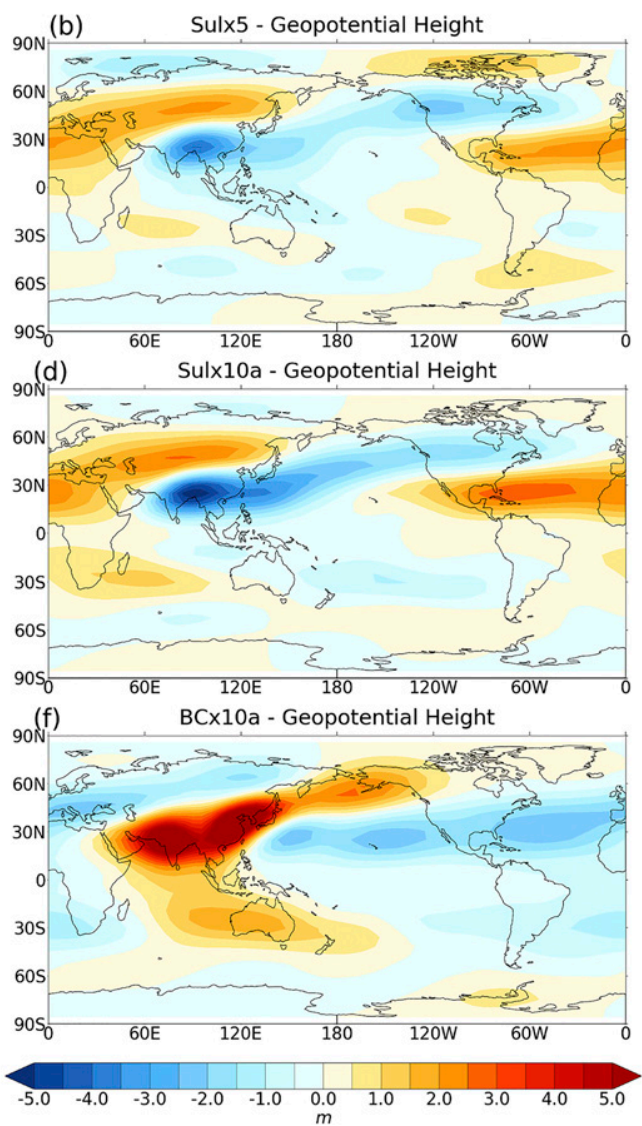

FIG. 11. LUMA steady-state responses $(\sigma=0.35)$ of (a),(c),(e) meridional wind $\left(\mathrm{m} \mathrm{s}^{-1}\right)$ and (b),(d),(f) geopotential height $(\mathrm{m})$ due to diabatic heating from the NDJFM mean precipitation responses in the (a),(b) Sulx5 and (c),(d) Sulx10a and (e),(f) from the NDJFM mean precipitation and atmospheric absorption in the BCx10a experiments.

The hypothesis put forward by Smith et al. (2016) posits that weakening of the Aleutian low is, in part, due to modulation of the Walker circulation. We find near-surface temperature warming in the North Atlantic relative to the North Pacific resulting from differential sulfate loading (evident in the Sulx10a coupled experiment, not shown). These conditions have been shown to be conducive to a strengthening of the Walker circulation (McGregor et al. 2014; Qin et al. 2020). Therefore, the mechanism posited by Smith et al. (2016) could explain the difference in strength of Aleutian low response between the fixed SST and coupled model setups, but a detailed analysis of this mechanism is beyond the scope of this study.

The transient simulations used by Smith et al. (2016) and Oudar et al. (2018) incorporated multiple aerosol species with the combined effect being considered to be primarily a consequence of increasing sulfate emissions in China. Given the much larger change in sulfate emissions with respect to black carbon emissions worldwide, this is a reasonable assumption; however, here we have shown that increased black carbon emissions over Asia drives a weakening of the Aleutian low, and this could compound any effects from increasing sulfate emissions. For instance, Smith et al. (2016) found a horseshoe pattern in near-surface temperature trends over the North Pacific in response to transient changes in aerosol emissions, corresponding to a negative PDO (their Fig. 2d), which resembles most closely the response we see to BCx10 (Fig. 2a).

The weakening of the Aleutian low in response to $\mathrm{BC}$ is in agreement with the results of Johnson et al. (2019), who showed that in response to tenfold increase in $\mathrm{BC}$ emissions with SSTs held constant, a pattern of lower-tropospheric zonal wind anomalies in the North Pacific that is indicative of a weakened Aleutian low. The studies of Johnson et al. (2019) and Mahajan et al. (2013) found that under two different experimental setups (atmosphere only and mixed layer ocean, respectively), diagnostics such as top-of-atmosphere radiative forcing, global mean surface temperature, precipitation, and cloud cover scale linearly in response to different BC scaling factors. This allows us to make tentative assumptions regarding the linearity of the Aleutian low response to a spatially constant change in $\mathrm{BC}$ loading. Additionally, our results concur with Teng et al. (2012) who showed, using a fully coupled 
atmosphere-ocean model, a weakened Aleutian low in boreal winter in response to a tenfold increase in Asian carbonaceous aerosol concentrations. Our finding of a more robust weakening of the Aleutian low to $\mathrm{BCx} 10$ in comparison with $\mathrm{BCx} 10 \mathrm{a}$ suggests that sources of $\mathrm{BC}$ outside of Asia and their complex climate processes and feedbacks also play a fundamental role in modulating the strength of the Aleutian low.

The diversity of model responses to the sulfate perturbations in tandem with the findings from Oudar et al. (2018) highlight the difficulty in identifying robust regional responses to sulfate aerosol forcing. It is difficult to ascertain whether any of the responses identified here are likely to be realistic, since each model differs in its climatology and representation of aerosol processes, including the representation of aerosol-radiation and aerosol-cloud interactions. Richardson et al. (2019) used results from "double call" radiation experiments for a subset of PDRMIP models to show that the top of atmosphere instantaneous radiative forcing from aerosol-radiation interactions in $\mathrm{BCx} 10$ has considerable spread across models (see variable "IRF toa" in their Fig. 1). Richardson et al. (2019) also found considerable intermodel spread in the effective radiative forcing across PDRMIP models in response to both sulfate and BC perturbations, which may cause uncertainty in the North Pacific response. However, there is no systematic disparity in North Pacific responses between models that do and do not include indirect aerosol effects for both BC and sulfate aerosols. It is plausible that the more robust response of the Aleutian low to $\mathrm{BC}$ aerosol is due to the dominance of the aerosol shortwave absorption, whereas for sulfate aerosols the pattern of anomalous precipitation is important (cf. Wilcox et al. 2019) and this differs across models.

The discrepancies between the steady-state response to the diabatic heating anomalies in the linear stationary wave model and the results from the PDRMIP models should be contextualized by reminding the reader of the limitations of the linear model. One limitation is the absence of a fully integrated ocean model, which has been shown to be integral in assessing aspects of the climate response to aerosol forcing (Zhao and Suzuki 2019). Another limitation is that the heating from black carbon absorption was estimated using a single offline radiative transfer model that differs from that used in many of the climate models. Another factor is that, for the sake of convenience, the mean precipitation anomalies were imposed even if they were not statistically significant, which raises the potential for a component of climate noise to influence the LUMA results. Therefore, these simplifications must be taken into account when comparing the results of the linear model with the comprehensive climate models. Nevertheless, LUMA is useful for demonstrating aerosol-induced teleconnections from remote regions that have the potential to influence the Aleutian low.

The assessment of the relative importance of latent and radiative heating induced by aerosols must be further caveated with the fact that most global climate models are only partially capable of investigating the complex interaction between aerosols and shallow and deep convective cloud systems (Wang et al. 2014). The authors further highlighted discrepancies in the North Pacific between a climate model that uses cloud parameterization to represent deep convection and an embedded regional cloud-resolving model that is able to explicitly resolve cloud updrafts. Hence, the development of improved cloud-aerosol microphysical schemes will facilitate future investigation of the dynamical responses to aerosol forcing.

\section{Conclusions}

Past literature has provided an inconsistent picture of the influence of anthropogenic aerosol emissions on the North Pacific atmospheric circulation and the PDO. We have used simplified model experiments with large, idealized aerosol forcings to investigate potential mechanisms through which changes in aerosol emissions affect the North Pacific.

Overall, our results show a robust weakening of the Aleutian low due to a global tenfold increase in black carbon, which is partly driven by local emissions from East Asia but also shows a significant role for BC sources outside of East Asia in influencing the North Pacific. However, a fivefold increase in global sulfate aerosol and a tenfold increase in sulfate aerosol over Asia both produce responses that do not project strongly onto the climatological Aleutian low. This differs from the findings of Smith et al. (2016) and Oudar et al. (2018), who showed that in coupled climate models a transient increase in anthropogenic aerosols over Asia leads to a weakening of the Aleutian low, though there are differences in the magnitude, pattern, and time scale of the aerosol forcing imposed in our experiments that prevent a like-for-like comparison with those studies.

The relative importance of ocean feedbacks for the responses to the BC and sulfate perturbations experiments was identified from the comparison of the coupled and fixed SST PDRMIP simulations, as well as with the LUMA model, which neglects ocean feedbacks. The robust weakening of the Aleutian low in response to BCx10 and BCx10a in the coupled and fixed SST experiments indicates a small role for ocean feedbacks. This is in contrast to the sulfate perturbation experiments where the MMM changes in NPI reverse sign from negative to positive in the fixed SST and coupled experiments, respectively.

We find the direct radiative effect is a considerably more important source of diabatic heating than the anomalous latent heating induced by the aerosol's role in cloud formation. The aerosol heating induces remote responses through anomalous Rossby wave source regions. We find diabatic heating over both India and China are important contributors to the North Pacific response in $\mathrm{BCx} 10$ through generation of Rossby wave trains that impact downstream of the heating. The linear response reproduces the pattern of North Pacific response to $\mathrm{BCx} 10 \mathrm{a}$ albeit less robustly; however, it does not reproduce the pattern in response to Sulx5. This indicates that the linearized primitive equation model neglects some key processes that determine the North Pacific response to a global increase in sulfate aerosols.

There remain substantial uncertainties in the global and regional forcing from anthropogenic aerosols. For example, at least $20 \%$ of the present uncertainty in simulated direct radiative forcing from $\mathrm{BC}$ is due to diversity in the vertical 
distribution of aerosol mass (Samset et al. 2013). Idealized sensitivity studies can therefore provide insights to the potential mechanisms that induce remote effects from aerosol forcing and have the advantage of achieving a larger signal that can be identified thereby overcoming some of the challenges of investigating the historical period when aerosols and greenhouse gases have been changing simultaneously.

Our results show that aerosols, and in particular, black carbon, can modulate the strength of the Aleutian low and induce surface temperature anomalies in the North Pacific that resemble the PDO. Future work will focus on investigating the atmospheric bridge from the North Pacific and its role for the PDO.

Acknowledgments. WJD was supported by a Natural Environment Research Council (NERC) Ph.D. studentship through the SPHERES Doctoral Training Partnership (NE/ L002574/1) and by a Met Office CASE studentship. ACM was supported by NERC (NE/M018199/1) and the European Union's Horizon 2020 Research and Innovation Programme under Grant Agreement 820829 (CONSTRAIN project). CJS was supported by a NERC/IIASA Collaborative Research Fellowship (NE/T009381/1). We are grateful to the PDRMIP project for providing the climate model simulations used in this study (https://www.cicero.oslo.no/en/PDRMIP). We are grateful to Anna Lewinschal and Steven Chan for assistance in converting the precipitation anomalies to diabatic heating profiles. We thank Piers Forster, Gunnar Myhre, Laura Wilcox, Andrea Dittus, Doug Smith, and Robert Allen for helpful suggestions on the work. We thank the three anonymous reviewers whose suggestions helped to improve the manuscript. ACM suggested the study. WJD performed the analysis, ran the LUMA simulation and produced all figures. ML assisted with setting up and testing LUMA and interpreting the results. CJS performed the SOCRATES calculations. WJD and ACM wrote the manuscript with input from ML and CJS.

Data availability statement. The PDRMIP data are publicly available: https://www.cicero.oslo.no/en/PDRMIP/PDRMIPdata-access. The LUMA simulations are available on request from the corresponding author.

\section{REFERENCES}

Alexander, M. A., and J. D. Scott, 2008: The role of Ekman ocean heat transport in the Northern Hemisphere response to ENSO. J. Climate, 21, 5688-5707, https://doi.org/10.1175/ 2008JCLI2382.1.

Allen, R. J., J. R. Norris, and M. Kovilakam, 2014: Influence of anthropogenic aerosols and the Pacific decadal oscillation on tropical belt width. Nat. Geosci., 7, 270-274, https://doi.org/ 10.1038/ngeo2091.

Arora, V. K., and Coauthors, 2011: Carbon emission limits required to satisfy future representative concentration pathways of greenhouse gases. Geophys. Res. Lett., 38, L05805, https:// doi.org/10.1029/2010GL046270.

Bartlett, R. E., M. A. Bollasina, B. B. B. Booth, N. J. Dunstone, F. Marenco, G. Messori, and D. J. Bernie, 2018: Do differences in future sulfate emission pathways matter for near-term climate? A case study for the Asian monsoon. Climate Dyn., 50, 1863-1880, https://doi.org/10.1007/s00382-017-3726-6.
Bellouin, N., J. Rae, A. Jones, C. Johnson, J. Haywood, and O. Boucher, 2011: Aerosol forcing in the Climate Model Intercomparison Project (CMIP5) simulations by HadGEM2ES and the role of ammonium nitrate. J. Geophys. Res., 116, D20206, https://doi.org/10.1029/2011JD016074.

Bentsen, M., and Coauthors, 2013: The Norwegian Earth System Model, NorESM1-M-Part 1: Description and basic evaluation. Geosci. Model Dev., 6, 687-720, https://doi.org/10.5194/ gmdd-5-2843-2012.

Boucher, D., and Coauthors, 2013: Clouds and aerosols. Climate Change 2013: The Physical Science Basis, T. F. Stocker et al., Eds., Cambridge University Press, 571-657, https://www.ipcc.ch/site/ assets/uploads/2018/02/WG1AR5_Chapter07_FINAL-1.pdf.

Chan, S. C., and S. Nigam, 2009: Residual diagnosis of diabatic heating from ERA-40 and NCEP reanalyses: Intercomparisons with TRMM. J. Climate, 22, 414-428, https://doi.org/10.1175/ 2008JCLI2417.1.

Charlson, R. J., S. E. Schwartz, J. M. Hales, R. D. Cess, J. A. Coakley Jr., J. E. Hansen, and D. J. Hofmann, 1992: Climate forcing by anthropogenic aerosols. Science. 255, 423-430, https://doi.org/10.1126/science.255.5043.423.

Chen, X., and J. M. Wallace, 2015: ENSO-like variability: 19002013. J. Climate, 28, 9623-9641, https://doi.org/10.1175/JCLID-15-0322.1.

- , and - 2016: Orthogonal PDO and ENSO indices. J. Climate, 29, 3883-3892, https://doi.org/10.1175/JCLI-D-150684.1.

Copernicus Climate Change Service, 2017: ERA5: Fifth generation of ECMWF atmospheric reanalyses of the global climate. Copernicus Climate Change Service Climate Data Store, accessed 1 April 2020, https://cds.climate.copernicus.eu/ \#!/search?text $=$ ERA5\&type $=$ dataset.

Dai, A., J. C. Fyfe, S. P. Xie, and X. Dai, 2015: Decadal modulation of global surface temperature by internal climate variability. Nat. Climate Change, 5, 555-559, https://doi.org/10.1038/ nclimate2605.

Delworth, T. L., F. Zeng, A. Rosati, G. A. Vecchi, and A. T. Wittenberg, 2015: A link between the hiatus in global warming and North American drought. J. Climate, 28, 3834-3845, https://doi.org/10.1175/JCLI-D-14-00616.1.

Dufresne, J. L., and Coauthors, 2013: Climate change projections using the IPSL-CM5 Earth System Model: From CMIP3 to CMIP5. Climate Dyn., 40, 2123-2165, https://doi.org/10.1007/ s00382-012-1636-1.

Edwards, J. M., and A. Slingo, 1996: Studies with a flexible new radiation code. I: Choosing a configuration for a large-scale model. Quart. J. Roy. Meteor. Soc., 122, 689-719, https://doi.org/10.1002/ qj.49712253107.

England, M. H., and Coauthors, 2014: Recent intensification of wind-driven circulation in the Pacific and the ongoing warming hiatus. Nat. Climate Change, 4, 222-227, https://doi.org/ 10.1038/nclimate2106.

Fyfe, J. C., and Coauthors, 2016: Making sense of the early-2000s warming slowdown. Nat. Climate Change, 6, 224-228, https:// doi.org/10.1038/nclimate2938.

Gent, P. R., and Coauthors, 2011: The Community Climate System Model version 4. J. Climate, 24, 4973-4991, https://doi.org/ 10.1175/2011JCLI4083.1.

Giorgetta, M. A., and Coauthors, 2013: Climate and carbon cycle changes from 1850 to 2100 in MPI-ESM simulations for the Coupled Model Intercomparison Project phase 5. J. $A d v$. Model. Earth Syst., 5, 572-597, https://doi.org/10.1002/ jame.20038. 
Hansen, J., M. Sato, and R. Ruedy, 1997: Radiative forcing and climate response. J. Geophys. Res., 102, 6831-6864, https:// doi.org/10.1029/96JD03436.

Held, I. M., M. Ting, and H, Wang, 2002: Northern winter stationary waves: Theory and modeling. J. Climate, 15, 2125-2144, https:// doi.org/10.1175/1520-0442(2002)015<2125:NWSWTA>2.0.CO;2.

Hodnebrog, Ø., and Coauthors, 2019: Water vapour adjustments and responses differ between climate drivers. Atmos. Chem. Phys., 19, 12 887-12 899, https://doi.org/10.5194/acp-19-128872019.

Hoskins, B. J., and A. J. Simmons, 1975: A multi-layer spectral model and the semi-implicit method. Quart. J. Roy. Meteor. Soc., 101, 637-655, https://doi.org/10.1002/qj.49710142918.

— , and D. J. Karoly, 1981: The steady linear response of a spherical atmosphere to thermal and orographic forcing. J. Atmos. Sci., 38, 1179-1196, https://doi.org/10.1175/15200469(1981)038<1179:TSLROA > 2.0.CO;2.

Hu, S., and A. V. Fedorov, 2017: The extreme El Niño of 2015-2016 and the end of global warming hiatus. Geophys. Res. Lett., 44, 3816-3824, https://doi.org/10.1002/2017GL072908.

Hua, W., A. Dai, and M. Qin, 2018: Contributions of internal variability and external forcing to the recent Pacific decadal variations. Geophys. Res. Lett., 45, 7084-7092, https://doi.org/ 10.1029/2018GL079033.

Huang, J., Y. Xie, X. Guan, D. Li, and F. Ji, 2017: The dynamics of the warming hiatus over the Northern Hemisphere. Climate Dyn., 48, 429-446, https://doi.org/10.1007/s00382-016-3085-8.

Hurrell, J. W., and Coauthors, 2013: The Community Earth System Model: A framework for collaborative research. Bull. Amer. Meteor. Soc., 94, 1339-1360, https://doi.org/10.1175/BAMS-D12-00121.1.

Iversen, T., and Coauthors, 2013: The Norwegian Earth System model, NorESM1-M-Part 2: Climate response and scenario projections. Geosci. Model Dev., 6, 389-415, https://doi.org/ 10.5194/gmd-6-389-2013.

Johnson, B. T., J. M. Haywood, and M. K. Hawcroft, 2019: Are changes in atmospheric circulation important for black carbon aerosol impacts on clouds, precipitation, and radiation? J. Geophys. Res. Atmos., 124, 7930-7950, https://doi.org/ 10.1029/2019JD030568.

Joshi, M., and J. Gregory, 2008: Dependence of the land-sea contrast in surface climate response on the nature of the forcing. Geophys. Res. Lett., 35, L24802, https://doi.org/10.1029/ 2008GL036234.

Kang, S. M., I. M. Held, D. M. W. Frierson, and M. Zhao, 2008: The response of the ITCZ to extratropical thermal forcing: Idealized slab-ocean experiments with a GCM. J. Climate, 21, 3521-3532, https://doi.org/10.1175/2007JCLI2146.1.

Kasoar, M., D. Shawki, and A. Voulgarakis, 2018: Similar spatial patterns of global climate response to aerosols from different regions. npj Climate Atmos. Sci., 1, 12, https://doi.org/10.1038/ s41612-018-0022-z.

Kay, J. E., and Coauthors, 2015: The Community Earth System Model (CESM) large ensemble project: A community resource for studying climate change in the presence of internal climate variability. Bull. Amer. Meteor. Soc., 96, 1333-1349, https://doi.org/10.1175/BAMS-D-13-00255.1.

Kim, J. W., S. W. Yeh, and E. C. Chang, 2014: Combined effect of El Niño-Southern Oscillation and Pacific decadal oscillation on the East Asian winter monsoon. Climate Dyn., 42, 957-971, https://doi.org/10.1007/s00382-013-1730-z.

Kirkevåg, A., and Coauthors, 2013: Aerosol-climate interactions in the Norwegian Earth System Model-NorESM1-M.
Geosci. Model Dev., 6, 207-244, https://doi.org/10.5194/gmd-6207-2013.

Kosaka, Y., and S. P. Xie, 2013: Recent global-warming hiatus tied to equatorial Pacific surface cooling. Nature, 501, 403-407, https://doi.org/10.1038/nature12534.

Lewinschal, A., A. M. L. Ekman, and H. Körnich, 2013: The role of precipitation in aerosol-induced changes in Northern Hemisphere wintertime stationary waves. Climate Dyn., 41, 647-661, https://doi.org/10.1007/s00382-012-1622-7.

Liakka, J., J. Nilsson, and M. Löfverström, 2012: Interactions between stationary waves and ice sheets: Linear versus nonlinear atmospheric response. Climate Dyn., 38, 1249-1262, https:// doi.org/10.1007/s00382-011-1004-6.

Liu, L., and Coauthors, 2018: A PDRMIP multimodel study on the impacts of regional aerosol forcings on global and regional precipitation. J. Climate, 31, 4429-4447, https://doi.org/ 10.1175/JCLI-D-17-0439.1.

Liu, Z., and M. Alexander, 2007: Atmospheric bridge, oceanic tunnel, and global climatic teleconnections. Rev. Geophys., 45, RG2005, https://doi.org/10.1029/2005RG000172.

Mahajan, S., K. J. Evans, J. J. Hack, and J. E. Truesdale, 2013: Linearity of climate response to increases in black carbon aerosols. J. Climate, 26, 8223-8237, https://doi.org/10.1175/JCLI-D-12-00715.1.

Mantua, N. J., and S. R. Hare, 2002: The Pacific decadal oscillation. J. Oceanogr., 58, 35-44, https://doi.org/10.1023/A:1015820616384.

Martin, G. M., and Coauthors, 2011: The HadGEM2 family of Met Office Unified Model climate configurations. Geosci. Model Dev., 4, 723-757, https://doi.org/10.5194/gmd-4-723-2011.

McGregor, S., and Coauthors, 2014: Recent Walker circulation strengthening and Pacific cooling amplified by Atlantic warming. Nat. Climate Change, 4, 888-892, https://doi.org/ 10.1038/nclimate2330.

Myhre, G., and Coauthors, 2017: PDRMIP: A Precipitation Driver and Response Model Intercomparison Project-Protocol and preliminary results. Bull. Amer. Meteor. Soc., 98, 1185-1198, https://doi.org/10.1175/BAMS-D-16-0019.1.

Neale, R. B., and Coauthors 2010: Description of the NCAR Community Atmosphere Model (CAM 5.0). NCAR Tech. Note NCAR/TN-464+STR, 214 pp., www.cesm.ucar.edu/ models/cesm1.1/cam/docs/description/cam5_desc.pdf.

Newman, M., 2007: Interannual to decadal predictability of tropical and North Pacific sea surface temperatures. J. Climate, 20, 2333-2356, https://doi.org/10.1175/JCLI4165.1.

— , G. P. Compo, and M. A. Alexander, 2003: ENSO-forced variability of the Pacific decadal oscillation. J. Climate, 16, 3853-3857, https://doi.org/10.1175/1520-0442(2003)016<3853: EVOTPD $>2.0 . \mathrm{CO} ; 2$.

— visited. J. Climate, 29, 4399-4427, https://doi.org/10.1175/ JCLI-D-15-0508.1.

Nidheesh, A. G., M. Lengaigne, J. Vialard, T. Izumo, A. S. Unnikrishnan, and C. Cassou, 2017: Influence of ENSO on the Pacific decadal oscillation in CMIP models. Climate Dyn., 49, 3309-3326, https://doi.org/10.1007/s00382-016-3514-8.

Otto-Bliesner, B. L., and Coauthors, 2016: Climate variability and change since $850 \mathrm{CE}$ : an ensemble approach with the Community Earth System Model. Bull. Amer. Meteor. Soc., 97, 787-801, https://doi.org/10.1175/BAMS-D-14-00233.1.

Oudar, T., P. J. Kushner, J. C. Fyfe, and M. Sigmond, 2018: No impact of anthropogenic aerosols on early 21 st century global temperature trends in a large initial-condition ensemble. Geophys. Res. Lett., 45, 9245-9252, https://doi.org/10.1029/ 2018 GL078841. 
Qin, M., A. Dai, and W. Hua, 2020: Aerosol-forced multidecadal variations across all ocean basins in models and observations since 1920. Sci. Adv., 6, eabb0425, https://doi.org/10.1126/ sciadv.abb0425.

Richardson, T. B., and Coauthors, 2018: Drivers of precipitation change: An energetic understanding. J. Climate, 31, 96419657, https://doi.org/10.1175/JCLI-D-17-0240.1.

_ and Coauthors, 2019: Efficacy of climate forcings in PDRMIP models. J. Geophys. Res., 124, 12 824-12 844, https://doi.org/ 10.1029/2019JD030581.

Samset, B. H., and Coauthors, 2013: Black carbon vertical profiles strongly affect its radiative forcing uncertainty. Atmos. Chem. Phys., 13, 2423-2434, https://doi.org/10.5194/acpd-12-28929-2012.

—_, and Coauthors, 2016: Fast and slow precipitation responses to individual climate forcers: A PDRMIP multimodel study. Geophys. Res. Lett., 43, 2782-2791, https://doi.org/10.1002/ 2016GL068064.

—, M. T. Lund, M. Bollasina, G. Myhre, and L. Wilcox, 2019: Emerging Asian aerosol patterns. Nat. Geosci., 12, 582-584, https://doi.org/10.1038/s41561-019-0424-5.

Sardeshmukh, P. D., and B. J. Hoskins, 1988: The generation of global rotational flow by steady idealized tropical divergence. J. Atmos. Sci., 45, 1228-1251, https://doi.org/10.1175/15200469(1988)045<1228:TGOGRF > 2.0.CO;2.

Schmidt, G. A., and Coauthors, 2014: Configuration and assessment of the GISS ModelE2 contributions to the CMIP5 archive. J. Adv. Model. Earth Syst., 6, 141-184, https://doi.org/ 10.1002/2013MS000265.

Schneider, N., and B. D. Cornuelle, 2005: The forcing of the Pacific decadal oscillation. J. Climate, 18, 4355-4373, https://doi.org/ 10.1175/JCLI3527.1.

Smirnov, D., M. Newman, and M. A. Alexander, 2014: Investigating the role of ocean-atmosphere coupling in the North Pacific Ocean. J. Climate, 27, 592-606, https://doi.org/ 10.1175/JCLI-D-13-00123.1.

Smith, D. M., and Coauthors, 2016: Role of volcanic and anthropogenic aerosols in the recent global surface warming slowdown. Nat. Climate Change, 6, 936-940, https://doi.org/ 10.1038/nclimate3058.

Smith, S. J., J. van Aardenne, Z. Klimont, R. J. Andres, A. Volke, and S. D. Arias, 2011: Anthropogenic sulfur dioxide emissions: 1850-2005. Atmos. Chem. Phys., 11, 1101-1116, https://doi.org/ 10.5194/acp-11-1101-2011.

Takahashi, C., and M. Watanabe, 2016: Pacific trade winds accelerated by aerosol forcing over the past two decades. Nat. Climate Change, 6, 768-772, https://doi.org/10.1038/nclimate2996.

Takemura, T., T. Nozawa, S. Emori, T. Y. Nakajima, and T. Nakajima, 2005: Simulation of climate response to aerosol direct and indirect effects with aerosol transport-radiation model. J. Geophys. Res., 110, D02202, https://doi.org/10.1029/ 2004JD005029.

— and radiative forcing of soil dust aerosols at the Last Glacial Maximum. Atmos. Chem. Phys., 9, 9, https://doi.org/10.5194/ acp-9-3061-2009.

Teng, H., W. M. Washington, G. Branstator, G. A. Meehl, and J.-F. Lamarque, 2012: Potential impacts of Asian carbon aerosols on future US warming. Geophys. Res. Lett. 39, L11703, https:// doi.org/10.1029/2012GL051723.

Trenberth, K. E., 2015: Has there been a hiatus? Science, 349, 691692, https://doi.org/10.1126/science.aac9225.

, and J. W. Hurrell, 1994: Decadal atmosphere-ocean variations in the Pacific. Climate Dyn., 9, 303-319, https://doi.org/ 10.1007/BF00204745.

- G. W. Branstator, D. Karoly, A. Kumar, N.-C. Lau, and C. Ropelewski, 1998: Progress during TOGA in understanding and modeling global teleconnections associated with tropical sea surface temperatures. J. Geophys. Res., 103, 14 291-14324, https://doi.org/10.1029/97JC01444.

— J. T. Fasullo, G. Branstator, and A. S. Phillips, 2014: Seasonal aspects of the recent pause in surface warming. Nat. Climate Chang., 4, 911-916, https://doi.org/10.1038/nclimate2341.

Walters, D. N., and Coauthors, 2014: The Met Office Unified Model Global Atmosphere 4.0 and JULES Global Land 4.0 configurations. Geosci. Model Dev., 7, 361-386, https://doi.org/ 10.5194/gmd-7-361-2014.

Wang, Y., and Coauthors, 2014: Assessing the effects of anthropogenic aerosols on Pacific storm track using a multiscale global climate model. Proc. Natl. Acad. Sci. USA, 111, 68946899, https://doi.org/10.1073/pnas.1403364111.

— Jiang, 2020: Reduced European aerosol emissions suppress winter extremes over northern Eurasia. Nat. Climate Change., 10, 225-230, https://doi.org/10.1038/s41558-020-0693-4.

Watanabe, M., and Coauthors, 2010: Improved climate simulation by MIROC5: Mean states, variability, and climate sensitivity. J. Climate, 23, 6312-6335, https://doi.org/10.1175/2010JCLI3679.1.

Wilcox, L. J., N. Dunstone, A. Lewinschal, M. Bollasina, A. M. L. Ekman, and E. J. Highwood, 2019: Mechanisms for a remote response to Asian anthropogenic aerosol in boreal winter. Atmos. Chem. Phys., 19, 9081-9095, https://doi.org/10.5194/ acp-19-9081-2019.

Wills, R. C., T. Schneider, J. M. Wallace, D. S. Battisti, and D. L. Hartmann, 2018: Disentangling global warming, multidecadal variability, and El Niño in Pacific temperatures. Geophys. Res. Lett., 45, 2487-2496, https://doi.org/10.1002/2017GL076327.

Wood, T., and Coauthors, 2020: The Southern Hemisphere midlatitude circulation response to rapid adjustments and sea surface temperature driven feedbacks. J. Climate, 33, 96739690, https://doi.org/10.1175/JCLI-D-19-1015.1.

Zhang, K., and Coauthors, 2012: The global aerosol-climate model ECHAM-HAM, version 2: Sensitivity to improvements in process representations. Atmos. Chem. Phys., 12, 8911-8949, https://doi.org/10.5194/acp-12-8911-2012.

Zhang, Y., J. M. Wallace, and D. S. Battisti, 1997: ENSO-like interdecadal variability: 1900-93. J. Climate, 10, 10041020, https://doi.org/10.1175/1520-0442(1997)010<1004: ELIV $>2.0 . \mathrm{CO} ; 2$.

Zhao, S., and K. Suzuki, 2019: Differing impacts of black carbon and sulfate aerosols on global precipitation and the ITCZ location via atmosphere and ocean energy perturbations. J. Climate, 32, 5567-5582, https://doi.org/10.1175/JCLI-D18-0616.1. 